\title{
Switching Between Everyday and Scientific Language
}

\author{
Eric J. Blown ${ }^{1}$ - Tom G. K. Bryce ${ }^{1}$
}

Published online: 12 July 2016

(C) The Author(s) 2016. This article is published with open access at Springerlink.com

\begin{abstract}
The research reported here investigated the everyday and scientific repertoires of children involved in semi-structured, Piagetian interviews carried out to check their understanding of dynamic astronomical concepts like daytime and night-time. It focused on the switching taking place between embedded and disembedded thinking; on the imagery which subjects referred to in their verbal dialogue and their descriptions of drawings and play-dough models of the Earth, Sun and Moon; and it examined the prevalence and character of animism and figurative speech in children's thinking. Five hundred and thirty-nine children (aged 3-18) from Wairarapa in New Zealand (171 boys and 185 girls) and Changchun in China ( 99 boys and 84 girls) took part in the study. Modified ordinal scales for the relevant concept categories were used to classify children's responses and data from each age group (with numbers balanced as closely as practicable by culture and gender) analysed with KolmogorovSmirnov two-sample tests (at an alpha level of 0.05). Although, in general, there was consistency of dynamic concepts within and across media and their associated modalities in keeping with the theory of conceptual coherence (see Blown and Bryce 2010; Bryce and Blown 2016), there were several cases of inter-modal and intra-modal switching in both cultures. Qualitative data from the interview protocols revealed how children switch between everyday and scientific language (in both directions) and use imagery in response to questioning. The research indicates that children's grasp of scientific ideas in this field may ordinarily be under-estimated if one only goes by formal scientific expression and vocabulary.
\end{abstract}

Keywords Everyday and scientific language $\cdot$ Embedded and disembedded thinking $\cdot$ Switching - Animism and figurative speech · Astronomy · Daytime and night-time

Much of the published research into the acquisition of scientific ideas by young people has concentrated upon their growing accumulation of correct or appropriately expressed terms for important concepts. This paper explores the boundaries between such language and the communications which precede and pre-determine its character. The empirical research which

Tom G. K. Bryce

t.g.k.bryce@ strath.ac.uk

1 University of Strathclyde, Glasgow, Scotland 
we describe examines the language used by children to convey their understanding of basic ideas in earth science and astronomy. It focuses on both their everyday and their scientific speech repertoires and how they switch between them and use imagery in response to questioning. First, we look at the key literature concerning the difficulties which children encounter in learning the language of science.

\section{The Complex Language of Science}

In their stimulating book on teaching, Postman and Weingartner (1971) stated that a subject or discipline, such as science, "is a way of knowing, and whatever is known is inseparable from the symbols (mostly words) in which the knowing is codified" (p. 103). They argued powerfully that every teacher is a teacher of language, a view that was thereafter espoused by many concerned with the educational process, whether as practitioners determined to improve students' learning or as researchers keen to unravel the complexities of how young people develop cognitively. Wellington and Osborne (2001) noted that learning science is, in many respects, like learning a new language, with considerable complications, not least because "many of the hard conceptual words...have a precise meaning in science and sometimes an exact definition, but a very different meaning in everyday life" (p. 5). Some of our familiar everyday words are taken over by science. Words which we have long used to mean something rather general can have a particular meaning for scientists (e.g. children may use 'insect' for every creepy-crawly, but the biologist keeps it for a particular group of invertebrates). Some scientific terms are metaphors and therefore make for added difficulties when a child is listening to the words of a speaker using scientific language (e.g. a 'force field' bears little resemblance to a 'field' as far as young learners are concerned). The notion of action at a distance is a very demanding abstract idea. Bar et al. (1997) found that pupils (even up to 18 years of age in their study), while regarding gravity as a force that holds people on the Earth and causes things to fall downwards, did not relate it to the Newtonian idea of a force between two masses in space. As Wellington and Osborne (2001) observed, teaching science also involves "introducing new words in familiar contexts...but at other times in unfamiliar contexts" (p. 5).

Recognising these points, teachers and researchers need to proceed cautiously when young people use scientific words; uttering the words does not necessarily mean the terms are understood. As Lakoff and Johnson (1980, p. 233) stated, "understanding is only possible through the negotiation of meaning" (emphasis added). Reiterating this, Niebert et al. (2012) showed that in helping students to come to terms with how the scientific community uses terminology, helpful metaphors and analogies must be unpacked carefully in terms of students' own everyday lives and direct experiences. Unfortunately, in general, "teachers are not sophisticated in the way they teach good scientific language" (see Brown and Ryoo 2008). And if school science fails to get students talking and thinking like scientists, then "Rather than becoming scientifically literate, they become scientifically indifferent" (Aikenhead 2011, p. 10).

In the case of earth science and astronomy, a number of the object words are clear (the Sun, the Moon...) but, to the uninitiated, many others are confusing. For example, many young children take the word 'earth' to mean 'dirt' or 'soil' rather than 'planet Earth' which calls for caution when asking simple questions such as "Tell me about the Earth?" At a higher level, the distinctive meanings of the words star and planet are difficult to grasp and certainly it is not 
easy for the inexperienced eye to tell them apart, going simply by observations of the sky at night. Other ideas are even more difficult, for example: where the Earth's atmosphere 'stops' is conceptually challenging for secondary pupils; the teacher's explanation for the Milky Waythat cloudy band across the night sky - being "the view of our disc-shaped galaxy from the inside" takes more than a stretch of the imagination; and a 'light year' must seem simply weird to pupils - an expression surely intended to be confusing. Findings by Bailey et al. (2012) indicate that students commonly misidentify the light year as a measurement of time. Perhaps most difficult are the ideas which involve dynamic concepts, ones where the movements of celestial objects have to be envisioned together in order to grasp what comes about and why. The distinctions between rotation and revolution, for example, concerning the motion of the Earth on its axis in a day and around the Sun in a year; of the Moon and why we see only one face of it; the relative motions of the Earth, the Sun and the Moon which bring about eclipses; and so forth, certainly make big demands of primary school age and many older pupils. Later in this article, we focus upon dynamic concepts in order to illustrate how young children respond when questioned about their thoughts and 'active' images.

\section{The Developmental Perspective: Language Switching}

Children acquire vocabulary gradually, refining their familiar word usage by adopting more formal, scientific terminology through encouragement and pressure from their teachers and practising new expressions where they see fit. Researchers have argued for some time that the everyday knowledge that children have acquired, preschool and extra-school, sometimes referred to as their 'socialised knowledge', is highly robust and never fully replaced by formal scientific understanding. Children have to learn to move between the embedded modes of thinking determined by how they have managed the everyday world and the disembedded modes of thinking dictated by the abstract, symbolic world of the scientist (see Donaldson 1978). Perceptively, Solomon (1983a) concluded:

The deepest levels of understanding are achieved neither in the abstract heights of 'pure' physics, nor by a struggle to eliminate the inexact structures of social communication, but by the fluency and discrimination with which we learn to move between these two contrasting domains of knowledge.

Crossing back and forwards between everyday and scientific language (a 'switching' of different repertoires) is not symmetrical. Teachers, for example, may well challenge pupils orally using ordinary language or set out science questions in familiar contexts, thereby encouraging pupils to resort to their familiar ways of thinking. Crossing back to the symbolic world can be very challenging, as observant teachers know. Nevertheless, with greater confidence, learners can consolidate their use of scientific expressions and endeavour to use them in increasingly less familiar contexts. van Oers (1998) has argued that we do not simply learn to 'dis-embed' ideas, we actually learn to recontextualize our past notions and this is a progressive, iterative process. Whether so or not, it is important to acknowledge that a young person may use both forms of expression for an idea, at different times and in different contexts; the meaning the individual is actually working with might be the same.

The researcher needs to (i) assess how young people handle, in the vernacular, ideas which they will later describe scientifically and (ii) explore the transitions which are made as children become more linguistically discriminating in their vocabulary. Since the drive to achieve control of situations arises very early in life (Donaldson 1978), the transition from embedded 
to disembedded thinking must similarly have origins in the early years of childhood. In more recent times, we have certainly seen researchers focusing upon the preschool years to explore the transitions of concern. For example, Fleer's (2009) study looked into the 4-5-year-old children's concept formation in two early childhood settings (one rural and the other urban), in particular at the reciprocity between everyday and scientific thinking. Her findings indicated that the playful contexts did indeed help children to bring together their everyday ideas with scientific concepts.

A related matter is the use of animism and teleological explanations in humans, the latter where an ultimate purpose is used as a means of explaining a phenomenon rather than any postulated cause, e.g. 'The Moon plays at night and sleeps in the daytime'; 'the Moon glows at night so that we can see'; 'trees produce oxygen so that animals and humans can breathe'; etc. While we will say more about animism a little later, it is notable that, while contemporary science dismisses teleological argument, young children display notable preferences for it. Among school-aged children, Kelemen and Rosset (2009) observed that "teleological intuitions explicitly link to beliefs about intentional causality in nature... with children's ideas not straightforwardly explained by parental explanations...or ambient cultural religiosity" (p. 138). And Kelemen et al. (2012) further argued that the propensity for teleological explanation does not simply disappear with maturity and development. Some adult populations display broad teleological intuitions, at least some of the time or in some circumstances. Surprisingly, even professional physical scientists can display remnants of it in their thinking, particularly when they are forced to reason at speed, according to Kelemen et al. (2012) who state: "A religion-consistent default cognitive bias toward teleological explanation tenaciously persists and may have subtle but profound consequences for scientific progress” (p. 1). Also, through comparisons between Alzheimer's patients and healthy controls, teleological intuitions seem to reassert themselves when the coherence of knowledge is eroded by disease. These researchers therefore argue that, while extended education in science reduces tendencies to reason in inaccurate teleological ways, such propensities are masked rather than completely replaced. Hence, particularly with respect to young people, reasoning may display both scientific and everyday intuitive ideas.

\section{Scaffolding}

Several writers have focused upon how young people may be assisted to change from everyday to scientific language. Bruner (1966, 1986), Lemke (1990), Taber (2000), Driver et al. (2000), Newton (2002), Mercer et al. (2004) and, more recently, Brown and his coauthors (Brown and Ryoo 2008; Brown et al. 2010; Brown and Spang 2008), for example, concentrate on how thinking may be scaffolded (to use Bruner's term for the sociocultural learning process exemplified by Vygotsky's zone of proximal development (ZPD); see Foley 1994; Mooney 2000). From an ethnographic perspective, Brown and colleagues' work has emphasised the linguistic dimensions of scaffolding. Their premise is that "science instruction that does not seek to actively deconstruct science teaching into conceptual and language components runs the risk of negatively affecting students' conceptual understanding and Discursive Identity development" (Brown and Ryoo 2008, p. 532). As argued earlier by Lemke (1990) who, like Wellington and Osborne (2001), wrote about science as a foreign language, Brown and Ryoo advocated that science should be taught using a hybrid of language, by firstly introducing ideas in the vernacular using everyday vocabulary and secondly then requiring students to use scientific discourse. From a study of the sociolinguistic 
discourse of a science teacher, Brown and his co-researchers concluded that, "by including vernacular alternatives to science terms, students were given a vision of science that was connected to their collective experience" (Brown and Spang 2008, p. 731). They believe that "the acquisition of the academic language of science remains one of the most difficult aspects of students' science learning” (Brown et al. 2010, p. 1490). Lemke's (1990) firm recommendation was that

Teachers should express all semantic relations among terms, and all conceptual relationships for each topic, in ordinary colloquial language as well as in scientific language, insofar as possible, and clearly signal when they are using each.

And, according to Hsu and Roth's recent microanalysis of classroom interactions and dialogue, the discourse of science classrooms continues to be 'a heterogeneous mix of scientific and non-scientific language'. For them, "learning science is a process of appropriating authoritative discourse into internally persuasive discourse" (Hsu and Roth 2014, p. 729). Renshaw and Brown (2007) identify four formats of teacher classroom talk for integrating everyday and scientific discourse, referring to them as replacement, interweaving, contextual privileging and pastiche. They suggest that

Within one classroom episode, a teacher might deploy paraphrasing strategies to extend students' vocabulary (replacement); might invite students to converse about their experiences at home or with friends that connect with a curriculum topic (interweaving); might challenge students to consider the kinds of arguments and evidence that hold sway in this discussion (contextual privileging); and might bring together for consideration a number of plausible representations of a concept and reflect on how the array of representations assists a deeper understanding of the topic (pastiche) (Renshaw and Brown 2007, p. 544).

Picking up on the second point (interweaving), it is worth noting the impact which relatives have on the scientific sense-making of young people through the naturally occurring interactions and dialogue of family life. Ash (2004), for example, studying the reflective family conversations encountered during aquarium visits, argued that "family collaborative dialogues in nonschool settings can be the foundations for scientific ways of thinking" (p. 857). Tenenbaum and Callanan (2008) looked at parent-child conversations apparent both at home and while families attended a children's museum, detecting variations in the explanatory speech provided by parents depending on the amount of their own schooling. In a small study of parent and child interviews (conducted separately and specifically about the Moon), Venville et al. (2012) noted that children's idiosyncratic ideas were influenced not only by observation of physical factors in their environment but also through social interaction and cultural activities. The investigations by Jane and Robbins (2007) showed how grandparents often assisted children's acquisitions of science and technology ideas through the everyday interactions they have during childminding activities involving home computers, games, garden play, outdoor excursions and so forth.

\section{Theorising the Links Between Everyday and Scientific Language}

The promotion of scaffolding essentially reinstates everyday intuitive ideas as the foundation of later scientific learning. It replaces two earlier theories in one. Firstly, it annuls Piaget's stage theory by applying the Ausubelian principle that anything can be meaningfully taught to any 
child at any age provided care is taken to ascertain where the child is at and building on that. Secondly, it supersedes a conceptual change theory insofar as it not only accepts the reality of coexisting modes of thought and language but also utilises them to build new knowledge. Scaffolding is well exemplified by Socratic dialogue where the teacher (or interviewer) takes the child gradually to a higher level of thought by sensitive probing of what the child already knows in embryonic form. Piaget's collaborator, Claparède, categorised children's thought as 'syncretic' and adult thought as 'logical'. Syncretism represented the tendency "to merge diverse elements into one unarticulated image on the strength of some chance impression" (Vygotsky 2012, p. 118). Vygotsky himself described them as 'unorganized heaps' and viewed schooling, with its emphasis upon using language to talk about language, as the important factor in helping children to acquire scientific concepts. Logical thought develops in stages (very differently theorized by these psychologists), with Vygotsky stressing the role of social interaction between child and adults such as parents and teachers. While both he and Piaget acknowledged that the two types of language and thought - egocentric, everyday cognitions and scientific thinking - continue to coexist in the mind of any individual person, Vygotsky (2012) considered this to happen to a greater degree. In Thought and Language, he reasoned that everyday, spontaneous concepts and scientific concepts were in continual interaction. His zone of proximal development was the meeting place of everyday and scientific concepts. Using an example pertinent to the present study, Kozulin states in the foreword to the recent edition of Thought and Language that

[Vygotsky] indicated that there is a significant difference, even a conflict, between spontaneous concepts that we acquire in our everyday experience and that might be adequate for daily life (e.g. "The sun rises in the morning") and the corresponding academic concepts essential for scientific and technological reasoning ("What appears as a sunrise is the result of the rotation of the Earth around its axis") (Kozulin 2012, p. xviii).

See also John-Steiner et al. (1998) who "conceptualize everyday and scientific concepts as an interconnected dynamic system rather than as separate processes implied by dichotomous relationships" (p. 127). Interestingly, recent thinking concerning the nature of concepts draws a distinction between formal and functional concepts with Greeno (2012) seeing it as nearly parallel to Vygotsky's distinction between scientific concepts and everyday concepts. By including activities, particularly instructional activities, in a functional approach, the concepts of a discipline like science can be related to the information and activities that are in students' prior knowledge and understanding.

\section{Animism and Anthropomorphism in Young Children's Explanations}

Studies of children's explanations, not least those concerned with questions about the Earth and space, show that young children frequently invoke animism (where life or consciousness is attributed to inanimate objects) and also anthropomorphism (where human characteristics are ascribed in some of the detail). Examples of the former would include "The Sun is hiding behind the mountains" or, more metaphorically, "Plants love the Sun because he wants them to grow". Examples of the latter would include "The Man in the Moon eats it to make the sky dark" or "The Sun scares away the stars". The children's use of language with elements of animism, anthropomorphism, personification, analogy, simile and metaphor has been studied extensively worldwide (see Table 1 and notes). 


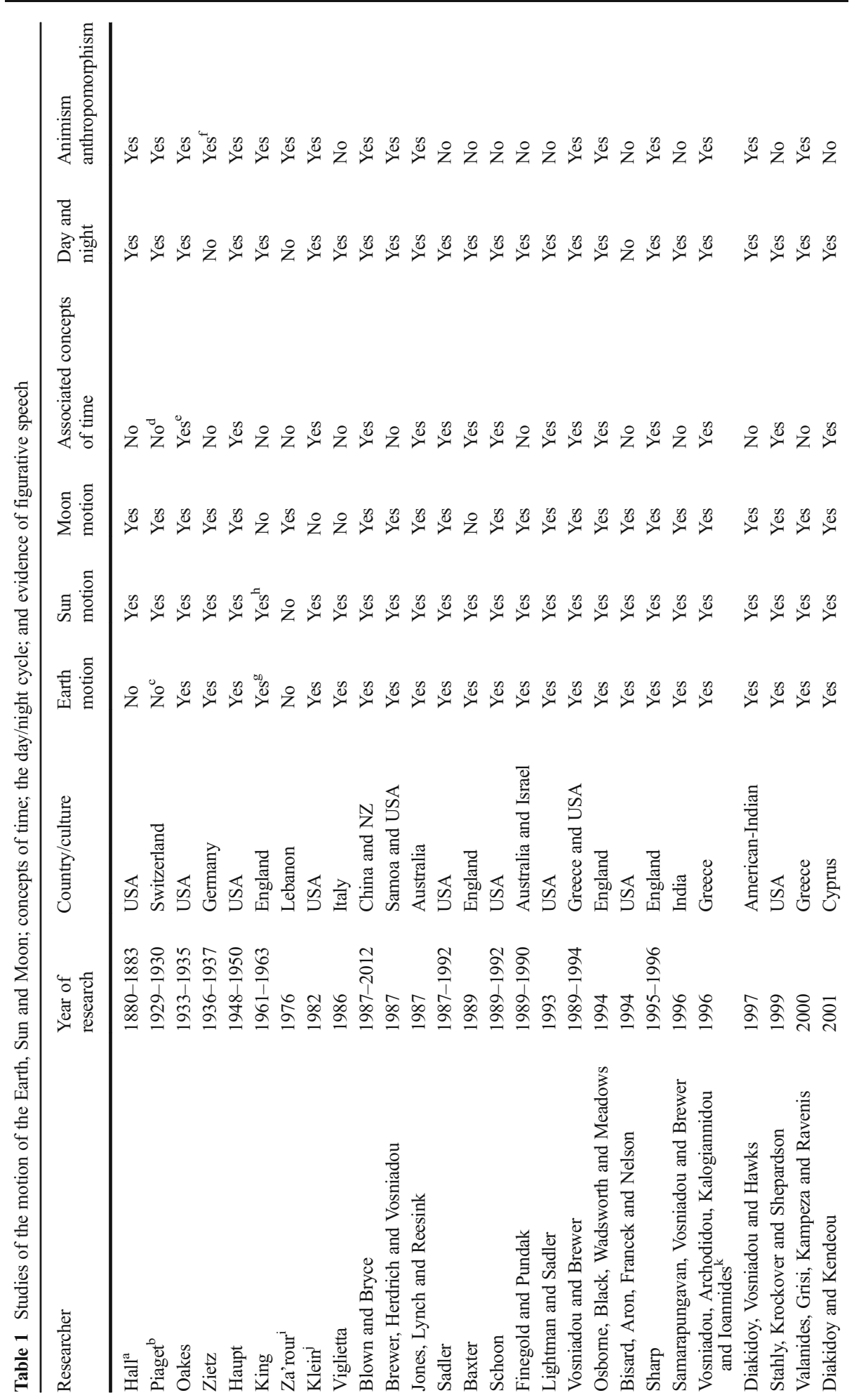




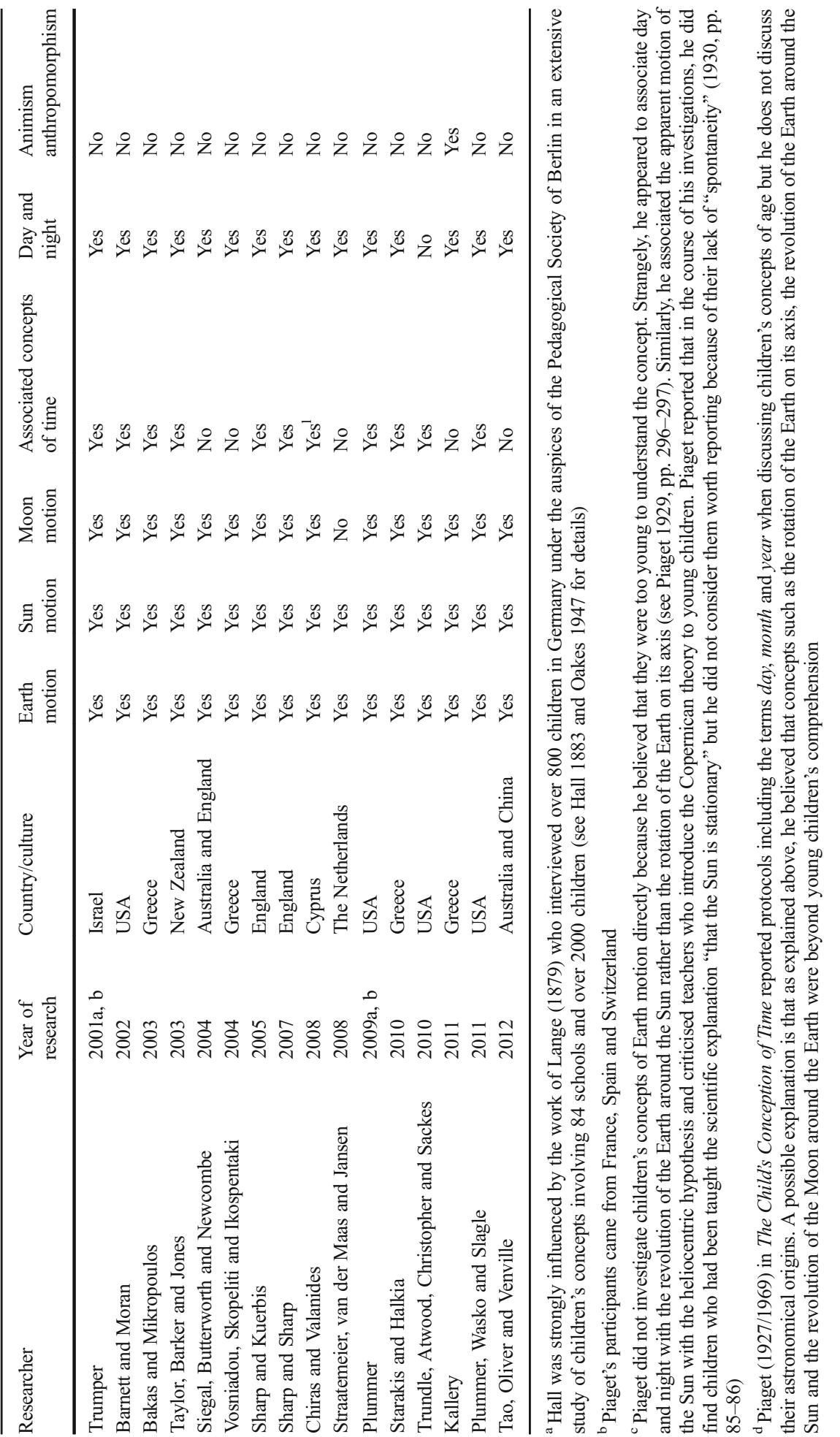




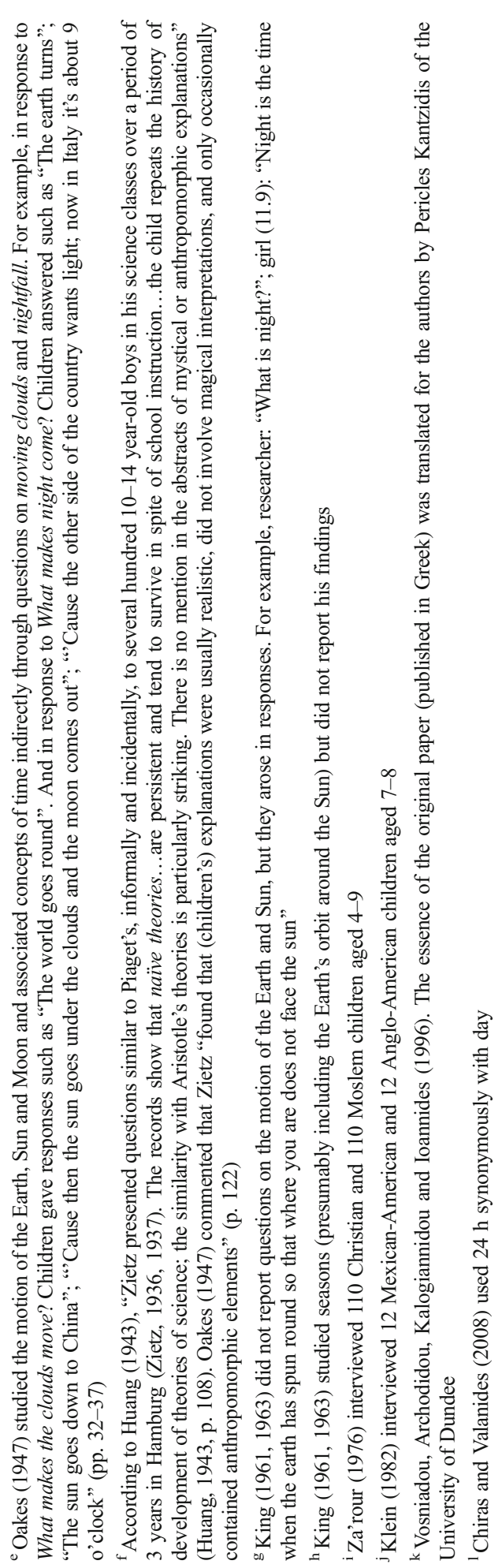


The researchers who have probed the children's use of figurative speech forms, such as "The Moon goes to bed to sleep during the daytime. The Sun goes to bed to sleep at nighttime", usually reveal that the child does not really believe that the Sun and Moon sleep as we sleep, or have beds as we have beds, but rather that they are not visibly active and, by analogy, are resting in some way, somewhere. A number of these researchers have concluded that when children resort to animistic expressions, they are essentially misapplying aspects of their acquired knowledge, including details gained through social traditions and storytelling. For example, Vosniadou (1989) concluded that children's notions are best explained by analogical thought involving "transferring an explanatory structure from one item to the other", e.g. from a different domain, rather than by general child animism as originally postulated by Piaget and others. While there is some evidence that early years teachers have concerns about their own use of animistic expressions (see Kallery and Psillos 2004), it would be wrong to dismiss the prevalence of animistic language in children as a 'nuisance' in the development of thinking. Researchers like Petrie (1979) recognised that metaphors generated through storytelling are actually constructive in relation to the development of scientific thinking. Petrie noted that "metaphor enables one to transfer learning and understanding from what is well-known to what is less well-known in a vivid and memorable way, thus enhancing learning" (p. 439). His argument was that metaphor is one of the main ways of "leaping the epistemological chasm between old knowledge and radically new knowledge” (p. 440). Thus, when children say that the Sun goes to bed at night or the Moon is sleeping during the day, they are speaking metaphorically as well as employing personification and analogy between the motions of heavenly bodies and the daily routines of human beings.

This has been put differently and more emphatically by those who focus upon language and cultural influences, and we should recognise that children are immersed in traditions which $d w e l l$ upon animistic ways of speaking (often in dynamic ways, to anticipate the next section). An almost daily adult expression in maritime climates is to speak of "the Sun trying to break through the clouds", which is completely unscientific, but it is what our children hear. Tempted though, we might be to say, in generalising from such observations, that language moulds the child, and it is probably more accurate to say that "it is the language which is already childish", as recorded a long time ago by Piaget as follows:

It is true that in everyday life there is often what Stern [sic] has called 'convergence' of the language used by parents towards a childish style of speech. Parents instinctively use easy expressions of a concrete and even animistic or anthropomorphic nature, so as to come down to the mental level of the child (Piaget 1926/1959, p. 98).

Nevertheless, some of the animism in the stories which many children regularly hear can give fairly firm underpinnings to wrong science and enduring misunderstandings. Integral to stories about Jack Frost, personifying frost and cold weather, nipping children's fingers and toes and making fern-like patterns on windows in cold winters, is that cold moves in and about, not that heat escapes from poorly insulated houses.

\section{Mental Imagery}

The role of mental imagery and imagination in the history of science is a little controversial. Famously, the ring structure of the benzene molecule and its complex bonding is said to have been revealed to August Kekulé through dynamic imagery in a dream about a snake which bit its own tail (see Gribben and Gribben 1998). Reacting to the difficulties in comprehending 
developments in physics at the start of the twentieth century, Piaget and Inhelder (1971), cited Juvet (1933) as having said "that it was impossible 'to carry on [atomic] physics with the imagination", that is with particular reference to the complexity of transformation systems in atomic physics. However, Einstein held imagery to be one of his own greatest assets using it to clarify ideas through thought experiments (see Blown and Bryce 2012). And more recently, Stephen Hawking has been forced through disability to rely on mental imagery to an unprecedented extent in his drive to solve the deepest problems in cosmology from the origin of the universe to the nature of black holes (see Bowie 2013).

Psychologists have long recognized that mental imagery in children develops through the practised remembering of previous perceptions which become, through time and with particular experiences, (a) progressively more anticipatory in nature and (b) increasingly more dynamic. Piaget and Inhelder (1971) had noted that images were essentially static up to roughly the onset of the concrete operational stage, approximately 7-8 years in most children. However, more recent research, such as that of Funk et al. (2005) has shown that children as young as 5 years have kinetic imagery (imagery representing movement) and that at least some features of it are guided by motor processes. Funk et al. argue that these are (internal, cognitive) mechanisms involving anticipation, though it remains unclear what is actually involved in the strategies concerned with imagining external things detached from our own bodies, like planetary movements. Utilising imaginary experiments where children were asked to predict when water would reach the rim of a tilted glass, Frick et al. (2009) have also shown that motor activities are important in supporting children's mental transformations. Through their investigations, it became clear that there are developmental trends for dynamic imagery. Notwithstanding such findings, writers like Pylyshyn (2003) conceded that we have still to understand whether mental images really do involve the inspection of spatially displayed picture-like objects or whether some different depiction is involved, that is, whether images are spatial, or representative in some other form, or analogue.

Static imagery has been studied using methods such as presenting drawings with incomplete features and asking subjects what they see; dynamic imagery studies have utilised thought experiments such as mental rotation tasks (see Funk et al. 2005; Piaget and Inhelder 1971). In order to ask children about their imagery, we used questions like: When I asked you about the Earth, Sun and Moon did you see any pictures in your imagination? or Did you see anything moving in your imagination? or When I asked you about the Earth and the Sun and the Moon and about things moving did you have any pictures in your mind of things moving? These readily solicit responses. Notwithstanding Pylyshyn's cautions, it is clear that an important part of a child's cognitive maturation is the bringing together of dynamic imagery and linguistically expressed ideas from either the everyday or the scientific repertoires of that child's language. Words and images are combined to render thinking more powerful, as in the thought experiments either naturally invoked by adults or quite deliberately used by teachers as part of instruction as well as those developed by scientists throughout history, many of them being recognised as significant to the evolution of scientific understanding (see Blown and Bryce 2012). In the empirical work described later, we give instances of children inter-connecting their imagined, visual images and their verbalised thoughts. These actions appear to be in keeping with the re-entry processes described by Edelman (2005) as children simulate concepts (see Bryce and Blown 2016; Barsalou 2003). 


\section{Research Question and Methodology}

The preceding review prompted us to investigate the coexistence of everyday and scientific language in the area of children's cosmologies and to gauge the extent of language switching between the two modes, whether unprompted or triggered by the contextual cues encountered through Socratic dialogue in Piagetian interviews. Our previous research into children's cognitive development in this area has made use of ordinal scales of core concepts (ranging from less scientific to more scientific). Thus, we reasoned that, as children try to explain dynamic concepts, switching should (a) be qualitatively apparent in protocols obtained through interviewing individuals and (b) show quantitatively as increases in concept category means with age (as measured with Kolmogorov-Smirnov (K-S) two-sample tests), irrespective of the language mode used in particular instances. We sought also to examine the extent of animism in children's responses, its decline (especially during the primary school years) and possible sources of figurative speech. Specifically then, our research question was as follows: Are both language modes evident in young children's responses and is language switching from everyday language (embedded thinking), including animism, to scientific language (disembedded thinking) — or vice versa — apparent during interviews?

The methodology used for the research reported here was based on the pioneering work of Nussbaum and Novak (1976) and Nussbaum (1979) and on our own previous investigations (see Bryce and Blown 2006, 2007, 2012, 2013; Blown and Bryce 2006, 2010, 2012). Our approach was also deeply influenced by Vygotsky's thesis which has profound implications for experimental data derived from Piagetian style interviews and Socratic dialogue or any other dialogue or questionnaire (written or verbal). And this is equally applicable to data derived from sociolinguistic methods. The authors have long recognised the need for great care in interview design to reduce the cultural bias of the researcher (particularly in cross-cultural studies) from an ethnographic perspective. We have also been aware of similar care to avoid restricting dialogue to the universal culture and language of science. These efforts were applied so as to elicit and probe children's own original ideas, expressed in everyday or scientific language (and shades inbetween). Vygotsky's work implies that no matter how we investigate, by the act of asking a question, we introduce a linguistic context which constrains or mediates the child's response. Importantly, it is vital that the interviewee has a sense of the interviewer's purposes in relation to the questions being asked. The researcher must make sure, as best he/she can, that there is a shared understanding with the child of what the exchange is all about. As Kozulin states "...it is not just the child's cognitive competence but also the negotiated sociocultural meaning of the situation that determines the child's performance" (Kozulin 2012, p. xv). The use of alternative media such as children's drawings and models is particularly helpful in this regard.

In the case of younger children, initial interviews investigated their concepts of the motion of the Earth and the apparent motion of the Sun by looking at changes in the shadow of a shadow stick, and observation of the motion of the Moon through study of its position and phases. In the main part of the interviews, the children were asked to draw the motion of the Earth, Sun and Moon and to give explanations for the associated concepts of time (day, year, month) and daytime/night-time. They then drew and modelled the shape of the Earth, Sun and Moon and used these to illustrate their dynamic concepts of the motions of these bodies. In addition to interviews, older children completed a preliminary written questionnaire. Because they afford the richest source of examples of language mode switching (a phenomenon difficult to capture in interviews and the principal emphasis of the research described here), children's explanations of daytime and night-time are the main focus of the analysis. However, 
the imagery reported (more commonly manifest in children's explanations and the secondary emphasis of the research) draws on all of the above areas of children's knowledge involving the shape and motion of the Earth, Sun and Moon.

\section{Sample, Surveys and Instruments}

There were 539 participants including 356 from New Zealand (171 boys and 185 girls) and 182 from China (99 boys and 84 girls). The children attended local kindergarten, primary and secondary schools in Wairarapa, Wellington Region, New Zealand, and Changchun, Jilin Province, (North East) China. The methodology utilised three data-gathering instruments: (a) for kindergarten, preschool and primary school children (aged 3-12), Piagetian interviews with three media: verbal language, drawing and play-dough modelling based on an extensive interview guide (see Bryce and Blown 2012), and (b) for middle school and high school students (aged 13-18), a written questionnaire inviting responses in writing and drawing combined with follow-up interviews and play-dough modelling to clarify ideas (see Bryce and Blown 2012 and Table 2).

Table 2 Survey participants by country, educational group, age, instrument and gender

\begin{tabular}{|c|c|c|c|c|c|c|c|c|c|}
\hline \multirow[t]{3}{*}{ Group } & \multirow[t]{3}{*}{ Age (years) } & \multirow[t]{3}{*}{ Instrument } & \multicolumn{6}{|c|}{ Country } & \multirow[t]{3}{*}{ Total } \\
\hline & & & \multicolumn{3}{|c|}{ New Zealand } & \multicolumn{3}{|c|}{ China } & \\
\hline & & & M & $\mathrm{F}$ & Total & $\mathrm{M}$ & $\mathrm{F}$ & Total & \\
\hline Kindergarten and preschool & $3-6$ & IG & 32 & 25 & 57 & 11 & 12 & 23 & 80 \\
\hline Junior primary school & $7-9$ & IG & 25 & 33 & 58 & 14 & 13 & 27 & 85 \\
\hline Senior primary school & $10-12$ & IG & 41 & 35 & 76 & 9 & 9 & 18 & 94 \\
\hline Middle school $^{\mathrm{a}}$ & $13-15$ & $\mathrm{Q}+\mathrm{FI}$ & 30 & 37 & 67 & 26 & 23 & 49 & 116 \\
\hline High school $^{\mathrm{b}}$ & $16-18$ & $\mathrm{Q}+\mathrm{FI}$ & 24 & 36 & 60 & 39 & 27 & 66 & 126 \\
\hline NZ pilot kindergarten & $3-5$ & IG & 10 & 9 & 19 & & & & 19 \\
\hline NZ pilot junior primary & $6-9$ & IG & 9 & 10 & 19 & & & & 19 \\
\hline Total & & & 171 & 185 & 356 & 99 & 84 & 183 & 539 \\
\hline
\end{tabular}

The interview guide, questionnaire and follow-up interview covered a wide range of topics on the motion and shape of the Earth, Sun and Moon (ESM); associated concepts of time; daytime and night-time; and gravity concepts utilising thought experiments about dropped and thrown balls, falling water and the path of a ball dropped into a hole through the Earth. Older children also studied seasons and eclipses. Language mode switching was apparent in all studies but was most evident in ESM motion studies particularly day/night studies. For this reason, the latter are reported in greater detail (see Tables 3 and 4). Some younger children did not participate in all studies so the number of participants in each study differed. The table above shows those children who participated in most of the ESM motion studies

$M$ male, $F$ female, $I G$ interview guide (Piagetian structured interview with Socratic dialogue), $Q$ written questionnaire (main points from interview guide), FI follow-up interview (probing responses with Socratic dialogue)

${ }^{\text {a }}$ Middle school $($ China $)=$ junior secondary $(\mathrm{NZ})$

${ }^{\mathrm{b}}$ High school $($ China $)=$ senior secondary $(\mathrm{NZ})$ 
Table 3 Frequency of intra-modal switching (within language modality) in day/night concepts

\begin{tabular}{|c|c|c|c|c|c|}
\hline \multirow[t]{2}{*}{ Age group } & \multirow[t]{2}{*}{ Age } & \multicolumn{2}{|l|}{$\mathrm{NZ}$} & \multicolumn{2}{|c|}{ China } \\
\hline & & $f / n^{\mathrm{a}}$ & $\%$ & $f / n$ & $\%$ \\
\hline Kindergarten and preschool & $3-5$ & $3 / 24$ & 12 & $3 / 22$ & 14 \\
\hline Junior primary school & $6-8$ & $7 / 28$ & 25 & $6 / 27$ & 22 \\
\hline Senior primary school & $9-12$ & $4 / 21$ & 19 & $3 / 18$ & 17 \\
\hline Junior secondary (middle) school & $13-15$ & $1 / 66$ & 2 & $1 / 49$ & 2 \\
\hline Senior secondary (high) school & $16-18$ & $1 / 51$ & 2 & $3 / 66$ & 4 \\
\hline
\end{tabular}

${ }^{a}$ Frequency of concept category divided by the number in the age group sampled

\section{Data Analysis, Categorisation and Coding}

The data from New Zealand and China were initially analysed, categorised and coded by the first author using a modified version of the cosmological concept categorisation scheme developed by the researchers (see Bryce and Blown 2006). The individual elements of the scheme included concepts of the motion and shape of the Earth, Sun and Moon; associated concepts of time; concepts of daytime and night-time; identity with and habitation of the Earth; and gravity. The coding instrument of each element consisted of an ordinal scale of concepts from least scientific (category 1) to most scientific (category 10), each concept being identified by a descriptor and illustrated by a thumbnail sketch (see Figs. 1, 2, 3 and 4 for modified versions of the scheme for Earth motion, Sun motion, Moon motion and daytime/night-time concepts). Where appropriate, elements were investigated by multi-media triangulation using interviews, drawing and play-dough modelling. Extension studies included investigation of the shape and motion of the planets of the Solar System, seasons and tides (see Appendices in Bryce and Blown 2006). The data were analysed using the $K-S$ two-sample test (alpha level 0.05 ) for comparison of category means between groups.

The written and verbal data from China were translated and transcribed by two interpreters/ research assistants who were familiar with the research methodology. The data were then analysed, categorised and coded in the same way as the data from New Zealand.

The cosmological concept categorisation scheme has been checked over a period of years by two astronomy educators with a wide experience in astronomy education from the Carter National Observatory, Wellington (see Bryce and Blown 2006, 2007, 2013; Blown and Bryce

Table 4 Frequency of inter-modal switching (across language, drawing and modelling) in day/night concepts

\begin{tabular}{|c|c|c|c|c|c|}
\hline \multirow[t]{2}{*}{ Age group } & \multirow[t]{2}{*}{ Age } & \multicolumn{2}{|l|}{$\mathrm{NZ}$} & \multicolumn{2}{|c|}{ China } \\
\hline & & $f / n$ & $\%$ & $f / n$ & $\%$ \\
\hline Kindergarten and preschool & $3-5$ & $5 / 24$ & 21 & $4 / 22$ & 18 \\
\hline Junior primary school & $6-8$ & $5 / 28$ & 18 & $4 / 27$ & 15 \\
\hline Senior primary school & $9-12$ & $2 / 21$ & 10 & $3 / 18$ & 17 \\
\hline Junior secondary (middle) school & $13-15$ & $4 / 66$ & 6 & $4 / 49$ & 8 \\
\hline Senior secondary (high) school & $16-18$ & $1 / 51$ & 2 & $3 / 66$ & 4 \\
\hline
\end{tabular}


2006, 2010). Exemplars for each category of the conceptual elements in each culture in the three media and their associated representing modalities were selected in each case. These represented approximately $20 \%$ of the data with 538 participants. The results verified the categorisation scheme with an inter-coder agreement of 92-96 \%; Cohen's kappa $(\kappa)=0.92$ to 0.94 .

\section{Findings}

The main data was in the form of verbal responses to interview questions asked of children aged 3-12 years and written responses to a questionnaire administered to older children aged 13-18 years, the latter being followed up by verbal questioning guided by the principles of Socratic dialogue. In addition, data were derived from children's drawings and play-dough models. Thus, the data were essentially qualitative in nature as represented in the sample protocols which follow. These responses were then categorised using the aforementioned scheme (see Figs. 1, 2, 3 and 4), frequencies expressed as percentages determined and group comparisons across media and cultures analysed using $K-S$ two-sample tests. The samples cited here have been chosen to give a spread of ethnicities, gender and age together with everyday and scientifically expressed ideas.

RQ: Are both language modes evident in young children's responses and is language switching from everyday language (embedded thinking), including animism, to scientific language (disembedded thinking)—or vice versa - apparent during interviews?

Although, in general, there was consistency of dynamic concepts within and across media and their associated modalities in keeping with the theory of conceptual coherence (see Blown and Bryce 2010), there was substantial evidence of children using both everyday and scientific language. There was also evidence of language mode switching from embedded to

\footnotetext{


10. Earth planet in space - Rotates (spins) on axis; Revolves in orbit around Sun or around Sun and Moon; Drawing: Spin indicated by axis of rotation and/or motion arrow(s)

9. Earth planet in space - Revolves in orbit around Sun; Does not spin or spin uncertain

8. Earth planet or ball-shaped object in space - Rotates (spins) on axis; Does not revolve (orbit) around Sun; Drawing: Spin indicated by axis and/or motion arrow(s)

7. Earth planet or ball-shaped object - Located in space or sky; Rotation (spin) and Revolution (orbit) around Sun uncertain; e.g., Moves continuously in some way; e.g., "from East to West", or "round and round", or "with the wind", or "across sky", or "rolls"

6. Earth of uncertain nature - Located in space or sky; Stationary or motion uncertain

5. Earth flat or disc-shaped or uncertain - Location also uncertain; Moves continuously in some way; e.g., "round and round", or "up and down", or "horizontally", or "rises and sets", or "moves around in circles", or "moves across sky"; Follows us when we move

4. Earth of uncertain nature - Location also uncertain; Motion irregular, or intermittent, or indirect, or uncertain, e.g., "only moves at night-time", or "trees move in the wind"

3. Earth animate: moves just like a person who "walks", "runs", "sleeps at night"; Does not spin at night "because it is tired"; "rolls", "lands on ground", "flies", "follows us"

2. Earth flat (slab, disc, pancake) or uncertain in nature - Location also uncertain; Stationary; Moves only during earthquakes; Drawing: Ground horizontal below; sky horizontal above

1. Uncertain of motion or nature or meaning of Earth - Not sure if/how Earth moves
}

Fig. 1 Ordinal scale for Earth motion concept categories 


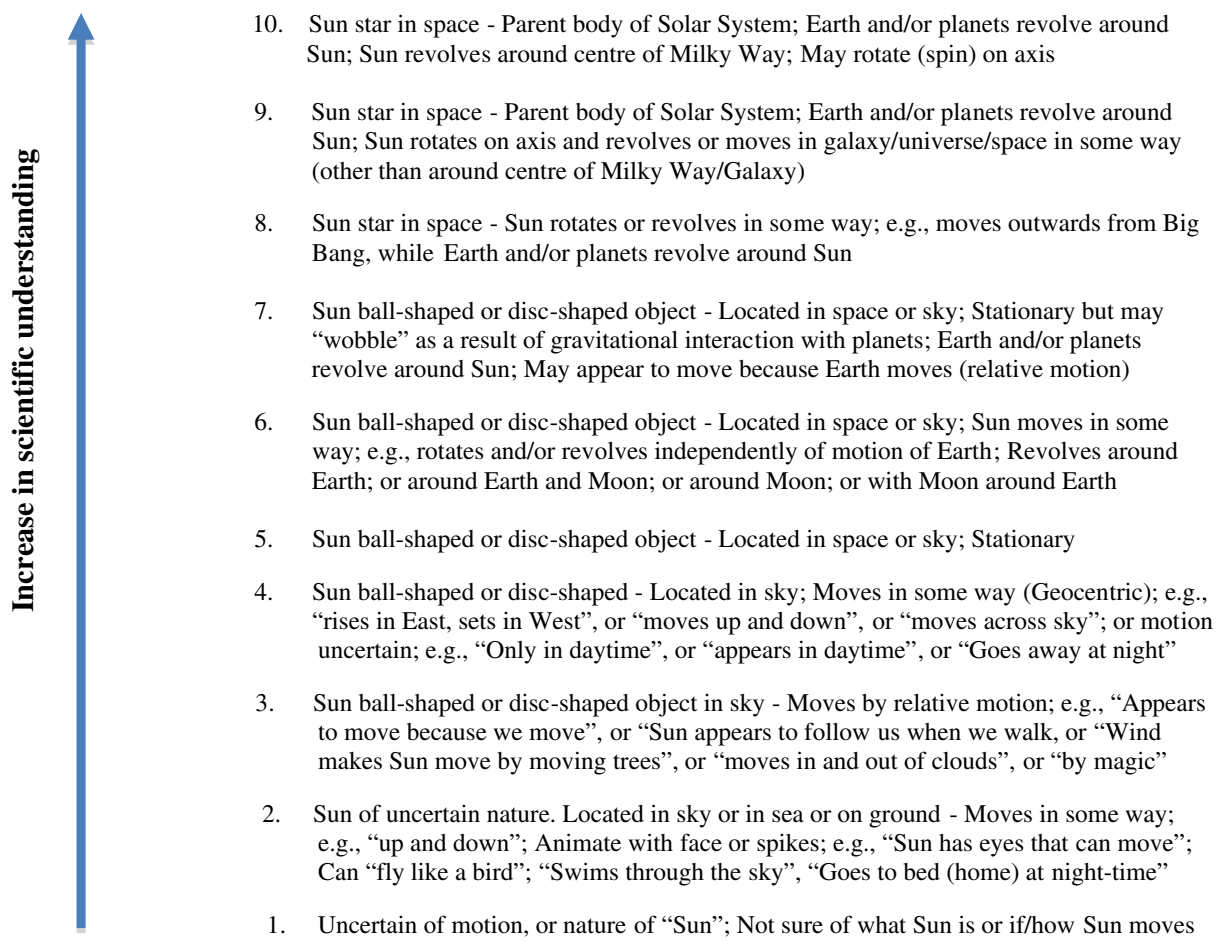

Fig. 2 Ordinal scale for Sun motion concept categories

disembedded repertoires and, in some cases, the reverse. Two distinct forms of switching were detected (although they become inter-twined through re-entry processes) (see Bryce and Blown 2016; Edelman 2005). The first kind is the familiar intra-modal one of verbal language where a child switches between everyday and scientific language. The second kind is the less common inter-modal one that we have detected through our multi-modal approach whereby children switch between verbal language, drawing and play-dough simulations of a concept such as the cause of daytime and night-time (see Barsalou 2003). Verbal intra-modal switching changes can be detected by close examination of verbal responses to interview questions and quantified using our cosmological concept categorisation scheme (see Figs. 1, 2, 3 and 4). These can be compared to responses from drawing and play-dough modelling modalities to look for inter-modal switching by comparing responses from category bands (animistic, semianimistic, everyday, semi-scientific and scientific, see Figs. 1, 2, 3 and 4; Table 4).

\section{Protocol Examples}

The following are protocol samples of the written questionnaire answers and verbal interview responses. Although we have identified protocol participants by culture (China and New Zealand (NZ)), ethnicity (NZ European, NZ Māori and Chinese Han), gender (male and female) and age (in years and months) for the interest of readers, we have restricted our analysis to culture (country). We have done so because our previous studies indicated a little variation between ethnicities and genders. Researcher's (R) questions are indicated in bold, 
10. Moon planet-like object - Natural satellite of Earth; Rotates (spins) on axis and revolves around Earth as Earth revolves around Sun; Gravitational pull of Sun and Moon causes tides on Earth. Tidally locked with Earth; period of rotation = period of revolution; "same side faces Earth"

9. Moon planet-like object - Located in space or sky; Revolves around Earth as Earth revolves around Sun, or around Earth and Sun, or Moon and Sun revolve around Earth, or Moon revolves around Earth as Sun revolves around Moon

8. Moon planet-like object - Located in space or sky; Moon does not revolve around Earth but moves with Earth as Earth revolves around Sun, or Moon revolves around Sun, or Earth and Moon revolve around Sun; Moon may rotate (spin)

7. Moon planet-like object - Located in space or sky; Moon does not revolve around Earth but remains stationary as Earth revolves around Sun, or Sun revolves around Earth, or Earth spins Moon may rotate (spin)

6. Moon planet-like object - Located in space or sky; Earth revolves around Moon, or around Sun and Moon

5. Moon planet-like object - Located in space or sky; Moves in some way; e.g., "Rises in East and sets in West", or "rolls", or "spins", or moves "up and down", or "across the sky", or revolves "in a circle", or "in circles"; "Comes out at night-time", or "moves at night-time"

4. Moon ball-shaped, or disc-shaped, or curved, or semi-circular object. - Located in space or sky; Stationary or motion uncertain or intermittent; e.g., "Comes out when it is dark", "Only moves at night-time", "Moon appears at night-time"; May "change to", or be "replaced by", or be "covered by" Sun or Earth

3. Moon object of uncertain nature - Located in space or sky; Stationary but appears to move (by relative motion); e.g., "Moon moves when we move"; "Moon appears to follow us when we walk, or drive, or go in a boat", or moves because of wind and/or relative to other objects in sky or atmosphere; e.g., "clouds push Moon", "moves because of Sun"

2. Moon object of uncertain nature - Located in sky; Animate; e.g., "Sleeps" during the day, "Plays" at night, "Gets up when the Sun goes to bed", "Gives out light when Sun goes to bed", "Walks across sky"; Moves in some way; e.g., "Rolls along ground"; May move by "magic", or by "Sand-man", or because "Jesus pushes it"

1. Uncertain of motion or nature or meaning of "Moon" - Not sure of what Moon is or if/how Moon moves

Fig. 3 Ordinal scale for Moon motion concept categories

italic font and children's (C) responses are indicated in plain, italic font. Following each illustration, statements are made [in square brackets] to indicate the switching of categories which individuals made in the course of their explanations. For example, daytime/night-time categories 1-4 represent everyday-animistic and semi-animistic ideas, 5-7 represent everyday non-animistic ideas and 8-10 represent scientific ideas (see Fig. 4). Hence, a move from categories 3 to 8 would indicate a switch from everyday to scientific thinking, as in the switch from "In daytime the Moon and Sun swap places" (category 3) to "Daytime and night-time are caused by the Earth spinning" (category 8).

(a) Examples of switching between coexisting 'everyday' and 'scientific' repertoires and vice versa

Responses to questionnaire: $N Z$

Rhiannon (NZ European: female, aged 13 years and 5 months)

Questions on daytime and night-time:

$\mathrm{R}$ : What is daytime?

$\mathrm{C}$ : The Sun is on that part of the world - the Sun is shining. 


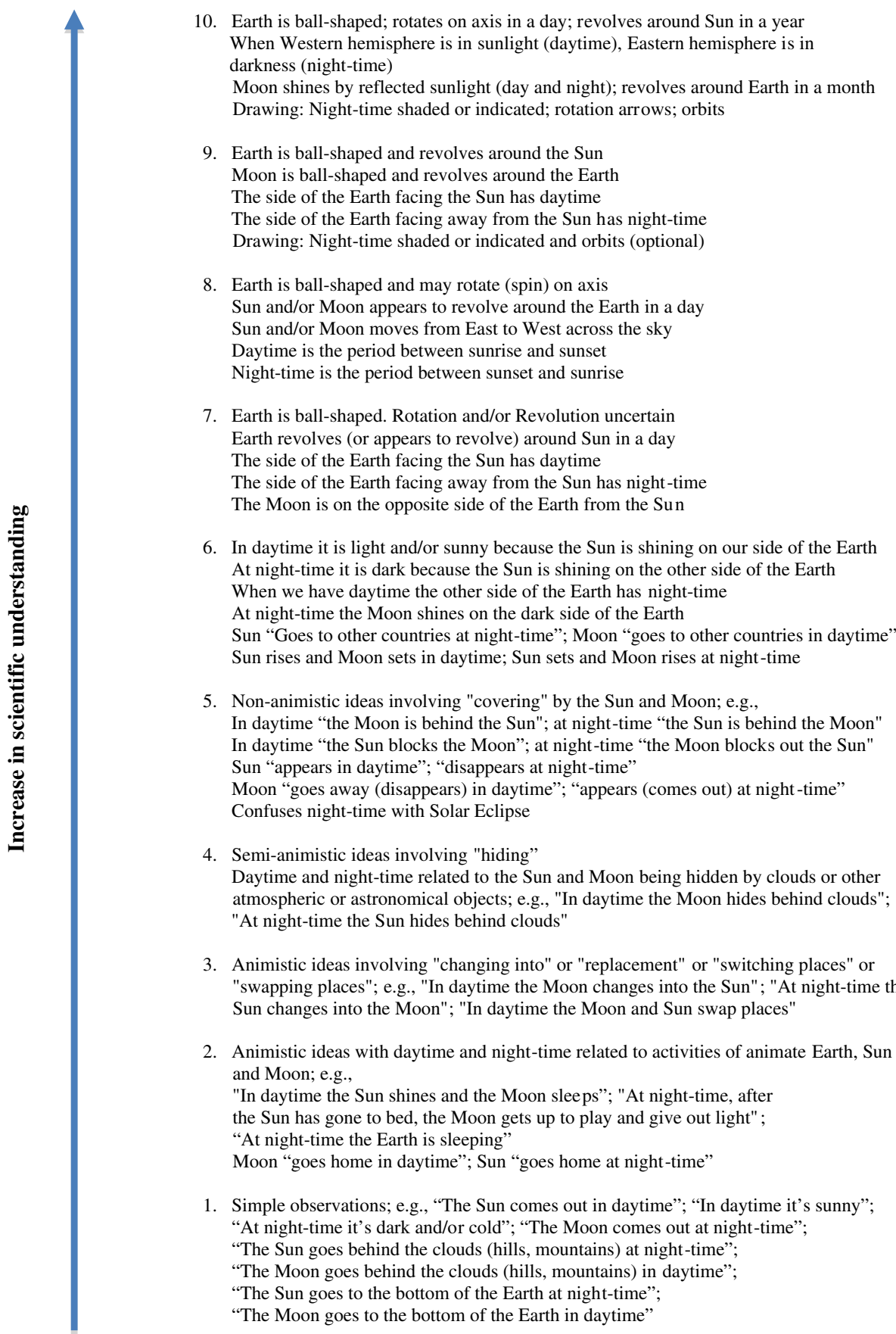

Fig. 4 Ordinal scale for daytime and night-time concept categories
$\mathrm{R}$ : What happens to the Earth in daytime?
$\mathrm{C}$ : It is light. 
R: What happens to the Sun in daytime?

$\mathrm{C}$ : It is shining and awake.

$\mathrm{R}$ : What happens to the Moon in daytime?

C: It sleeps.

[An intra-modal (within language modality) switch from daytime/night-time language concept category 6 (semi-scientific: the Sun is shining on part of the Earth) to daytime/ night-time concept category 1 (simple observation: it is light) to daytime/night-time concept category 2 (animistic: the Sun is awake; the Moon sleeps), also classified as Sun motion concept category 2 and Moon motion concept category 2] (see Figs. 2, 3 and 4)

Drawing of the Earth, Sun and Moon in daytime and night-time In both cases, Rhiannon showed the Earth, the Sun and the Moon scientifically but with everydayanimistic captions.

[An inter-modal (across language and drawing modalities) switch from daytime/night-time language concept category 9 (scientific: the Earth rotating on axis) to daytime/night-time concept category 2 (animistic: the Moon sleeping in daytime; the Sun sleeping at night-time)] (see Fig. 4)

Drawing of the Earth, Sun and Moon in daytime C: In her daytime drawing, Rhiannon drew the Moon with caption "zzz" to represent sleeping (see Fig. 5a(i)).

[An intra-modal (within drawing modality) switch from daytime/night-time drawing concept category 9 (scientific: the Earth rotating on axis with night-time shaded) to daytime/nighttime concept category 2 (animistic: the Moon sleeping)] (see Fig. 4)

$\mathrm{R}$ : What is night-time?

$\mathrm{C}$ : When the Sun is not shining.

$\mathrm{R}$ : What happens to the Earth at night-time?

C: It goes dark on one side.

$\mathrm{R}$ : What happens to the Sun at night-time?

C: It goes to sleep.

R: What happens to the Moon at night-time?

C: It comes into the sky.

[An intra-modal (within language modality) switch from daytime/night-time language concept category 1 (simple observation: the Sun is not shining) to daytime/night-time concept category 6 (everyday-semi-scientific: one side of the Earth goes dark) to daytime/night-time concept category 2 (animistic: the Sun sleeping) to daytime/night-time concept category 1 (simple observation: the Moon rises)] (see Fig. 4)

Drawing of the Earth, Sun and Moon at night-time C: Drew the Earth on axis; the Sun with caption "zzz" to represent sleeping (see Fig. 5a(ii)).

[An intra-modal (within drawing modality) switch from daytime/night-time drawing concept category 9 (scientific: the Earth rotating on axis with night-time shaded) to daytime/nighttime concept category 2 (animistic: the Sun sleeping)] (see Fig. 4)

Similarly in China, Li Jin Zhu drew the Earth, Sun and Moon scientifically but with animistic annotations (see Fig. 5b). These examples illustrate that (a) switching can take place in both directions, everyday to scientific and scientific to everyday; (b) switching can take 
place between verbal and drawing modes; and (c) animism can be represented pictorially as well as verbally.

Li Jin Zhu (China: Han: female, aged 5 years and 9 months)

$\mathrm{R}$ : What happens to the Earth at night-time?

C: The Earth falls asleep (see Fig. 5b).

$\mathrm{R}$ : What happens to the Sun at night-time?

a(i)

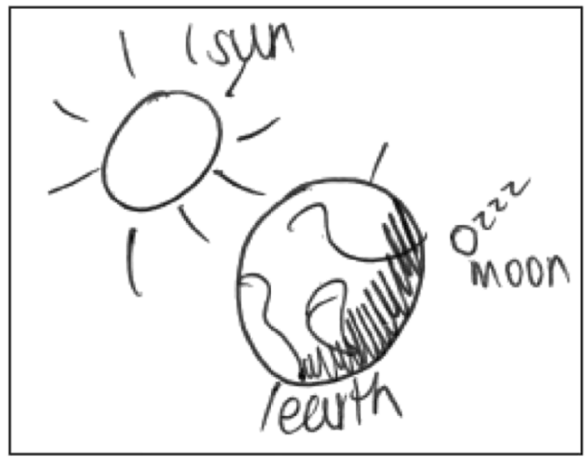

\section{a(ii)}

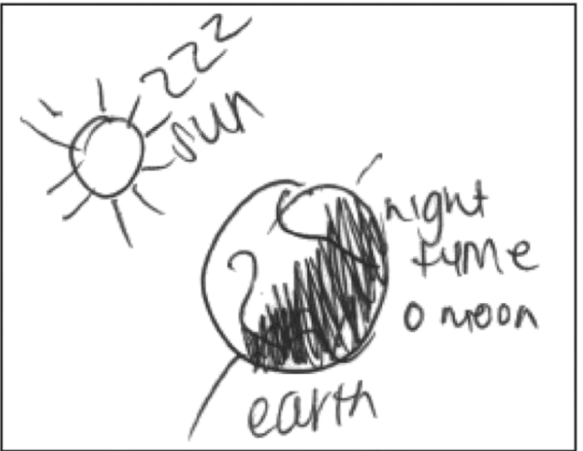

b

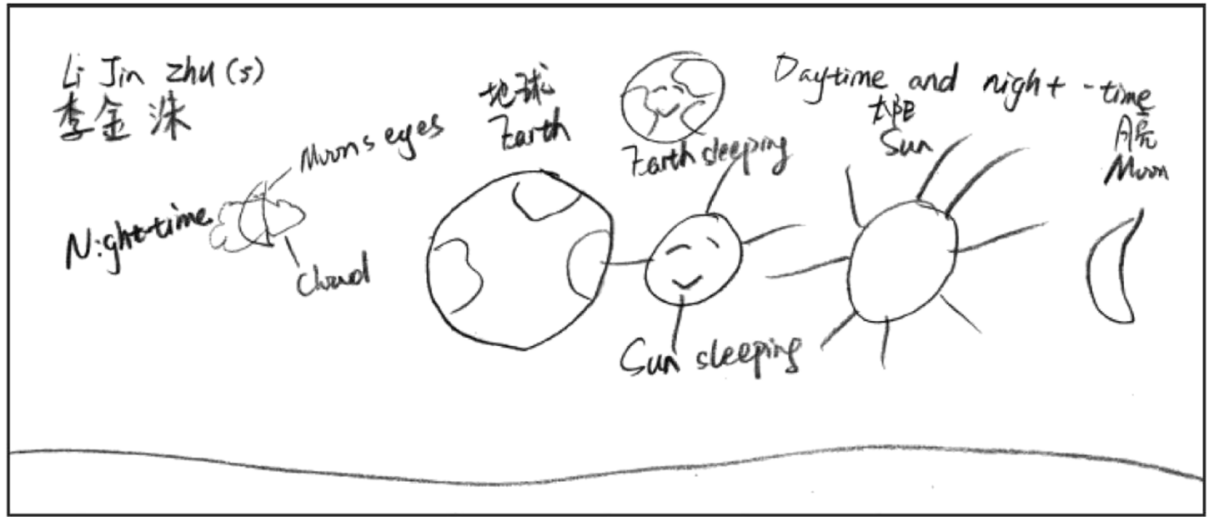

Fig. 5 a ( $i$ ) Daytime drawing: Rhiannon (NZ European: female, aged 13 years and 5 months) said that daytime is when "The sun is shining on that part of the world"; in daytime, the Earth is "light", the Sun is "awake" and the Moon "sleeps", which she indicates by "zzz" on her drawing. Note that the Earth has an axis of rotation, the surface of the Earth has features (continents and oceans), the night-time side of the Earth is shade and the Moon is smaller than the Earth and appears to be in the orbit around the Earth. Thus, her drawing combines both everyday and scientific concepts. a (ii) Night-time drawing: Rhiannon said that night-time is when "The Sun is not shinning on that part of the world"; at night-time, the Earth "goes dark on one side", the Sun "goes to sleep" and the Moon "comes out into the sky". In this case, she indicated the Sun sleeping by "zzz" on her drawing. As with her daytime, drawing combines both everyday and scientific concepts. b Daytime and night-time drawing: Li Jin Zhu (China: Han: female, aged 5 years and 9 months) said that daytime is "This moment"; in daytime, the Earth "wakes up", the Sun is "Hanging in the sky" and the Moon "sets behind the hill and goes to sleep". Night-time is "when in gets dark", and the Moon "also falls asleep at night time but it hangs in the sky and the cloud is its cover", which she indicates by closed eyes of the Earth, Sun and Moon in her drawing. Note: The researcher's interpreter labelled the drawing following Li Jin Zhu's instructions 
C: It sleeps at the foot of the hill.

$\mathrm{R}$ : What happens to the Moon at night-time?

C: The Moon also falls asleep at night-time but it hangs in the sky and the cloud is its cover.

[An inter-modal (across language and drawing modalities) switch from daytime/night-time language concept category 2 (animistic: the Earth, Sun and Moon sleep) to daytime/nighttime drawing concept category 6 (everyday-semi-scientific: dual Earth concept: one synonymous with ground; the other planet like in space/sky; the Sun and Moon associated with the Earth in space/sky) to daytime/night-time language concept category 2 (animistic: drawing captions show the Earth, Sun and Moon sleeping), also classified as Earth motion concept category 3, Sun motion concept category 2 and Moon motion concept category 2] (see Figs. 1, 2, 3 and 4)

(b) Examples of switching between coexisting everyday and scientific repertoires and vice versa Responses to questionnaire: China

$\mathrm{R}$ : What is a year?

Niu Sheng Shuang (China: Han: female, aged 17 years and 11 months)

According to an old legend, there was a monster called 'Year' who ate lots of people then was killed. According to science, a year starts from spring and ends in winter or from January to December.

[Time interview: a switch from "everyday-cultural" to scientific concept categories]

Switching was also evident in play-dough modelling. For example, it was not uncommon for children to change the shape of their models of the shape of the Earth from disc-shaped to ball-shaped as a result of Socratic dialogue. These changes in shape had implications for Earth motion and daytime/night-time concepts since a complete (scientific) understanding of the cause of the daytime/night-time cycle depends on knowing that the Earth is spherical (see Bryce and Blown 2016).

(c) Examples of switching between coexisting scientific and everyday repertoires

\section{Interview responses}

Aidan (NZ European: male, aged 7 years and 2 months)

R: Tell me about the Sun?

C: It's a star.

$\mathrm{R}$ : Where is the Sun?

C: In space — because it's a star.

$\mathrm{R}$ : Is the sun moving?

C: Yes.

$\mathrm{R}$ : How is the Sun moving?

C: It's moving slowly.

$\mathrm{R}$ : Why is the Sun moving?

C: Because of the wind.

$\mathrm{R}$ : The wind blows the Sun, does it?

C: Yes. 
[An intra-modal (within language modality) switch from Sun motion concept category 8 (scientific) to Sun motion concept category 3 (semi-animistic)] (see Fig. 2)

Tipene (NZ Māori: male, aged 11 years and 4 months)

R: What makes daytime and night-time?

$\mathrm{C}$ : It goes around.

$\mathrm{R}$ : What goes around?

C: The Earth.

$\mathrm{R}$ : What happens to the Moon at night-time?

C: It goes to sleep.

$\mathrm{R}$ : Where does it go to sleep?

$\mathrm{C}$ : Behind the mountains.

R: Do you think it really goes to sleep?

C: No.

R: Why do you say it goes to sleep?

C: I forgot (myself).

[An intra-modal (within language modality) switch from daytime/night-time concept category 8 (scientific) to daytime/night-time concept category 2 (animistic) and back to everyday language, also classified as Moon motion concept category 2] (see Figs. 3 and 4)

[When questioned about the sources of his ideas about the Earth, Sun and Moon (such as the Moon sleeping), Tipene said that his Mum and Dad told him stories about them].

Li Xin (China: Han: female, aged 8 years and 9 months)

R: Tell me about the Earth?

$\mathrm{C}$ : The Earth is round like a ball and many people live on the surface of it. There are many countries on the Earth.

R: Is the Earth moving?

C: Yes.

R: Why is the Earth moving?

C: It follows us.

R: [Earlier child said that the Sun followed us].

$\mathrm{R}$ : Is it the same as the Sun?

C: Yes.

[An intra-modal (within language modality) switch from Earth motion concept category 7 (semi-scientific) to Earth motion concept category 3 (animistic)] (see Fig. 1)

Bradley (NZ Māori: male, aged 9 years and 6 months)

$\mathrm{R}$ : What is daytime?

C: Daytime is when half the world would be away from (the Sun) and the other half would be towards (the Sun). [Daytime/night-time category 6]

$\mathrm{R}$ : Why is there daytime?

$\mathrm{C}$ : We have to have daytime so we won't get lost in the darkness. [Daytime/night-time category 1]

$\mathrm{R}$ : What is night-time?

C: Night-time is when one side (of the Earth) is dark and the other side (of the Earth) has got light. [Daytime/night-time category 6] 
$\mathrm{R}$ : Why is there night-time?

C: So you can rest and regain energy. [Daytime/night-time category 1]

$\mathrm{R}$ : What happens to the Earth at night-time?

C: It still rotates with the Moon on one side and the Sun on the other side where it is daylight. [Daytime/night-time category 9]

[Bradley represents a relatively rare case of a child alternating freely between everyday and scientific repertoires. Usually, children switch from everyday to scientific modes as a result of probing and Socratic dialogue. But, Bradley switches from scientific freely, without probing, to everyday then back to scientific then everyday and finally scientific.]

Viane (NZ Māori: female, aged 9 years and 1 month)

$\mathrm{R}$ : What is night-time?

C: It's when the Sun goes down and the Moon comes up and it's all lit up.

R: What happens to the Earth at night-time?

C: It spins round - it moves slowly.

$\mathrm{R}$ : What happens to the Sun at night?

It goes away for a while then it loses its sunshine and goes to sleep.

[Viane is an example of a child displaying inter-modal switching across language, drawing and play-dough modelling modalities. Her daytime/night-time concept by verbal language as in the interview extract was category 2 (animistic), by drawing (category 7, semi-scientific) and by play-dough modelling (category 6 , everyday). Sun animism also classified as Sun motion concept category 2] (see Figs. 2 and 4)

Caitlin R. (NZ European: female, aged 4 years and 7 months)

R: What happens to the Sun at night?

C: The Sun goes away.

$\mathrm{R}$ : Where does it go away to?

C: Its home.

R: Where's its home?

C: Somewhere else...

$\mathrm{R}$ : What does the Sun do when it gets to its home at night?

C: It goes to sleep.

R: What does the Moon do in daytime?

C: It goes back to sleep again (yawns, a pretend yawn).

[An intra-modal (within language modality) switch from daytime/night-time concept category 6 (everyday-semi-scientific: the Sun goes away (to other countries) at night-time) to daytime/night-time concept category 2 (animistic: the Sun goes to sleep at home), also classified as Sun motion concept category 2 and Moon motion concept category 2] (see Figs 2, 3 and 4)

Wang Yuan Yuan (China: Han: female, aged 8 years and 1 month)

R: What happens to the Earth at night-time?

$\mathrm{C}$ : It sleeps.

R: How does the Earth sleep?

C: It stops spinning.

$\mathrm{R}$ : Where does the Earth sleep?

$\mathrm{C}$ : In the sky. 
[An intra-modal (within language modality) switch from Earth motion concept category 3 (animistic: the Earth sleeps) to Earth motion concept category 8 (scientific: the Earth spins)] (see Fig. 1)

Li Zhong Qi (China: Han: male, aged 5 years and 3 months)

$\mathrm{R}$ : What happens to the Moon in daytime?

C: The Moon goes back to its home in daytime but I don't know where it goes.

$\mathrm{R}$ : What is night-time?

C: It gets dark at night-time. The Moon appears and the Sun goes back to its home.

$\mathrm{R}$ : What happens to the Sun at night-time?

C: The Sun sets at the foot of the hills.

[Li Zhong Qi is another example of a child displaying inter-modal switching. His daytime/ night-time concept by interview was category 2 (animistic), his drawing was classified as category 5 (non-animistic involving covering by the Sun and Moon) and his play-dough modelling was rated category 1 (everyday simple observations), also classified as Sun motion concept category 2 and Moon motion concept category 2] (see Figs 2, 3 and 4)

[Discussion: The idea that the Sun or Moon sets, or goes to rest, or sleeps, at the foot of, or behind, the hills or mountains is common to children in New Zealand and China. Mountains and hills surround Wairarapa, yet there are no mountains or hills visible in Changchun on the Northeast China Plain, raising the question of where these notions come from if not from personal experience based on observation (see main discussion).

When questioned more deeply about their animistic ideas, children sometimes give reactions which indicate that they are "thinking in two worlds" (see Solomon 1983a, b, c): in this case, one world is the cultural world of young children with its fairy tales, nursery rhymes and children's books; many of which do give human characteristics to the Sun and Moon in words and in illustrations. And the other world is that of adults, not necessarily scientifically inclined ones. It is as if, by probing deeper, one is waking the child up from one world (a dream like one) to the other world (the wide awake one).]

\section{Quantitative Data}

Turning to the quantitative data derived from the protocols, Table 3 shows the frequency of intra-modal switching. The results indicate that intra-modal switching (within the verbal language modality) is less common in the early years when children's language tends to be animistic or everyday rather than scientific: kindergarten and preschool (aged 3-5): NZ (12\%) and China (14\%). The frequency of intra-modal switching is at a maximum in the junior primary school years (aged 6-8): NZ (25\%) and China (22\%) when children predominantly use everyday and scientific language interchangeably. The frequency of switching drops slightly in the senior primary school (aged 9-12): NZ (19\%) and China (17\%), where everyday and scientific concepts coexist and compete as explanatory repertoires. Language mode switching is relatively rare at secondary level (2-4\%) where the scientific view dominates teaching in both cultures.

While Table 4 depicts the frequency of inter-modal switching, it can be seen that the frequency of switching across language, drawing and play-dough modelling modalities generally decreases with age. The percentage values range from $21 \%$ in kindergarten and preschool to $2 \%$ in senior secondary school in NZ and from $18 \%$ in kindergarten and 
preschool to $4 \%$ in high school in China. The reason for the slightly higher figure for senior primary school in China over senior primary school in NZ is probably due to differences in familiarity with the media: e.g. NZ children having greater opportunity to draw (see Bryce and Blown 2012) which would influence their ability to maximise that modality. Although treated as separate modalities, drawing and play-dough modelling were mediated by language. The interview was based on verbal questions from an extensive interview guide (for younger children) and a written questionnaire (for older children). For example, children were asked to draw the Earth, Sun and Moon at daytime and night-time; to make the shape of the Earth, Sun and Moon in play-dough; to model the motion of the Earth, Sun and Moon; and to model daytime and night-time with their models. As shown in the protocols, during these activities, they were asked questions about what they were doing. Older children were also asked about their written responses and invited to explain their drawings and modelling. Thus, verbal language was the dominant modality as it is in everyday life. Hence, our focus is on language mode switching as the primary source in intra-modal and inter-modal switching.

Table 5 illustrates the proportions of daytime and night-time concepts in each category (animistic and semi-animistic; everyday, non-animistic; scientific and semi-scientific). The results show animistic and semi-animistic concepts declining with age and gradually being replaced by (or coexisting with) everyday, non-animistic concepts and, finally, scientific concepts. The pattern is similar in both cultures. However, in general, a higher percentage of NZ children held animistic concepts: kindergarten and preschool (NZ $33 \%$; China $30 \%$ ), junior primary school (NZ $21 \%$; China $19 \%$ ) and senior primary school (NZ $14 \%$; China $6 \%$ ). And a higher number of China secondary school students held animistic or semianimistic concepts: junior secondary school (NZ $3 \%$; China $8 \%$ ) and senior secondary school (NZ $0 \%$; China $5 \%$ ).

Figure 6 shows the latter results diagrammatically as the percentage of children's responses to questions about daytime and night-time featuring animism by age group. The decline with age is readily apparent, but the proportions of pupils in secondary school still resorting to animism is equally striking (up to $8 \%$ ). Variations in the acquisition of everyday-non-animistic and scientific concepts are attributed to cultural and educational factors.

Table 5 Proportions of children's daytime and night-time concepts in each category by age groups

\begin{tabular}{|c|c|c|c|c|c|c|c|c|c|c|c|c|c|}
\hline \multirow[t]{4}{*}{ Age group } & \multirow[t]{4}{*}{ Age } & \multicolumn{12}{|c|}{ Daytime and night-time interview concept category } \\
\hline & & \multicolumn{4}{|c|}{$\begin{array}{l}\mathrm{D} / \mathrm{N} 2-4^{\mathrm{a}} \\
\text { Animistic and } \\
\text { semi-animistic }\end{array}$} & \multicolumn{4}{|c|}{$\begin{array}{l}\text { D/N 5-7 } \\
\text { Everyday- } \\
\text { non-animistic }\end{array}$} & \multicolumn{4}{|c|}{$\begin{array}{l}\text { D/N 8-10 } \\
\text { Scientific and } \\
\text { semi-scientific }\end{array}$} \\
\hline & & \multicolumn{2}{|l|}{ NZ } & \multicolumn{2}{|c|}{ China } & \multicolumn{2}{|l|}{ NZ } & \multicolumn{2}{|l|}{ China } & \multicolumn{2}{|l|}{$\mathrm{NZ}$} & \multicolumn{2}{|l|}{ China } \\
\hline & & $f / n$ & $\%$ & $f / n$ & $\%$ & $f / n$ & $\%$ & $f / n$ & $\%$ & $f / n$ & $\%$ & $f / n$ & $\%$ \\
\hline Kindergarten and preschool & $3-5$ & $8 / 24$ & 33 & $7 / 23$ & 30 & $5 / 24$ & 21 & $10 / 23$ & 43 & $2 / 24$ & 8 & $1 / 23$ & 4 \\
\hline Junior primary & $6-8$ & $6 / 28$ & 21 & $5 / 27$ & 19 & $12 / 28$ & 43 & $13 / 27$ & 48 & $9 / 28$ & 32 & $10 / 27$ & 37 \\
\hline Senior primary & $9-12$ & $3 / 21$ & 14 & $1 / 18$ & 6 & $9 / 21$ & 43 & $8 / 18$ & 44 & $10 / 21$ & 48 & $8 / 18$ & 44 \\
\hline Junior secondary & $13-15$ & $2 / 66$ & 3 & $4 / 49$ & 8 & $23 / 66$ & 35 & $15 / 49$ & 31 & $40 / 66$ & 61 & $27 / 49$ & 55 \\
\hline Senior secondary & $16-18$ & $0 / 51$ & 0 & $3 / 66$ & 5 & $15 / 51$ & 29 & $15 / 66$ & 23 & $36 / 51$ & 71 & $49 / 66$ & 74 \\
\hline
\end{tabular}

${ }^{\mathrm{a}}$ See Fig. 4 
Table 6 shows the results of the $K-S$ tests comparing concepts of daytime and night-time across cultures. The category mean figures $(M)$ illustrate the development of these with age (mean values rising from approx. 3 or 4 on our ordinal scale (c.f. Fig. 4) at kindergarten stages to more than 8 at senior secondary/high school stages) and the move from everyday-animistic through everyday-semi-animistic to scientific concepts in New Zealand and China.

Table 7 gives details of responses to questions about mental imagery as follows:

1. When I asked you about the Earth, Sun and Moon, did you think of any stories you have been told about them?

2. Did you see any words (in your imagination)?

3. Did you see any pictures (in your imagination)?

4. Did you see anything moving (in your imagination)?

For those children who indicated that the Earth and/or the Sun and/or the Moon moved:

5. When I asked you about the Earth and the Sun and the Moon and about things moving, did you have any pictures in your mind of things moving?

These were used to investigate the hypothesis that when children access alternative everyday and scientific language repertoires in memory, they also access alternative static and dynamic images as an integral part of conscious and unconscious re-entrant processes (see Bryce and Blown 2016). Static imagery refers to children imagining pictures of the Earth, Sun and Moon, whereas dynamic imagery refers to children visualising the motion of these bodies (both being relevant to children's concepts of daytime and night-time). It can be seen that both static and dynamic imagery increase with age: pictures of the Earth, Sun and Moon increasing from $40 \%$ in NZ kindergarten and preschool to $70 \%$ in NZ senior primary school and from $45 \%$ in China primary and preschool to $76 \%$ in China senior primary school. Similarly, with motion of the Earth, Sun and Moon, there was an increase from $40 \%$ in NZ kindergarten and preschool to $70 \%$ in NZ senior primary school and from $45 \%$ in China primary and preschool to $82 \%$ in China senior primary school. These changes suggest that skill in accessing and manipulating images is related to the growth of scientific language. We are currently unable to answer Pylyshyn's (2003) question about the nature of such images: whether they are spatial

Fig. 6 Percentage of children's responses featuring animism in particular age ranges concerning daytime and night-time concepts

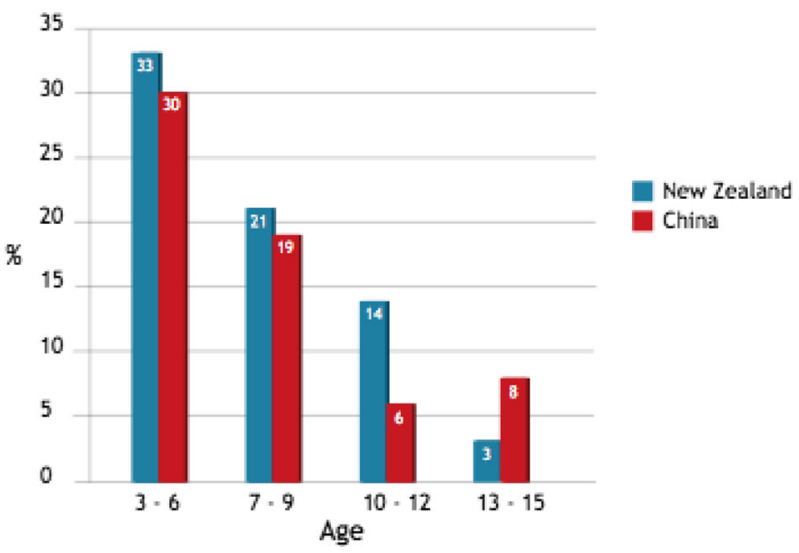


Table 6 Results of Kolmogorov-Smirnov tests comparing concepts of day and night across cultures

\begin{tabular}{lllll}
\hline Group & Number & $M$ & SD & $p$ value \\
\hline NZ kindergarten and preschool pupils & 24 & 3.25 & 2.44 & $>0.10$ \\
China kindergarten and preschool pupils & 23 & 3.65 & 2.30 & \\
NZ junior primary school pupils & 28 & 6.29 & 3.07 & $>0.10$ \\
China junior primary school pupils & 27 & 5.85 & 2.23 & \\
NZ senior primary school pupils & 21 & 7.29 & 1.90 & $>0.10$ \\
China senior primary school pupils & 18 & 7.50 & 2.75 & \\
NZ junior secondary school students & 66 & 7.92 & 2.08 & $>0.10$ \\
China middle school students & 49 & 7.06 & 2.74 & \\
NZ senior secondary school students & 51 & 8.43 & 1.88 & $<0.10$ \\
China high school students & 66 & 8.26 & 1.86 & \\
\hline
\end{tabular}

There were no significant differences between the two cultures as shown by the $p$ values. Rather than calculate an actual $p$ value, the $K-S$ test reports the region of a calculated probability. Hence, $p<0.10$ means that the actual value is between 0.10 and 0.05 , whereas $p>0.10$ simply means that the actual value is greater than 0.10 . In all five cases here, since the actual $p$ level is greater than 0.05 , one can conclude that the test is not significant at an alpha level of 0.05 . Inspection of the category means column $(M)$ shows that they tended to increase with age in both cultures

pictures or some other forms of representation or whether they may be non-representational (see Bryce and Blown 2016), but we have suggestions for further research.

\section{Conclusions and Discussion}

First, the evidence from children's responses to questions about the shape and motion of the Earth, Sun and Moon, and their explanations for daytime and night-time, indicates the coexistence of everyday and scientific language: the former grounded or embedded in cultural

Table 7 Details of responses to mental imagery questions

\begin{tabular}{|c|c|c|c|c|}
\hline \multirow[t]{3}{*}{ Group } & \multicolumn{2}{|c|}{ Static imagery } & \multicolumn{2}{|c|}{ Dynamic imagery } \\
\hline & \multicolumn{2}{|c|}{ Pictures of ESM } & \multicolumn{2}{|c|}{ Motion of ESM } \\
\hline & $f / n^{\mathrm{a}}$ & $\%$ & $f / n^{\mathrm{a}}$ & $\%$ \\
\hline NZ kindergarten and preschool & $4 / 10$ & 40 & $4 / 10$ & 40 \\
\hline China kindergarten and preschool & $5 / 11$ & 45 & $5 / 11$ & 45 \\
\hline NZ junior primary school & $8 / 14$ & 57 & $7 / 14$ & 50 \\
\hline China junior primary school & $8 / 15$ & 53 & $9 / 15$ & 60 \\
\hline NZ senior primary school & $7 / 10$ & 70 & $7 / 10$ & 70 \\
\hline China senior primary school & $13 / 17$ & 76 & $14 / 17$ & 82 \\
\hline
\end{tabular}

Static imagery = pictures of the Earth, Sun and Moon; dynamic imagery = images of the motion of the Earth, Sun and Moon

${ }^{\text {a }}$ Only those children who had concepts of the Earth, Sun and Moon were asked specific imagery questions 
context and the latter unfettered or disembedded as applied in the universal language of science. The evidence also suggests that these alternative repertoires are bonded to concepts - the strength of the bond being dependent on the concept-skill of the child. This concept-skill manifests as an ability to recreate or simulate (to use Barsalou's 2003 term) a concept such as the motion of the Earth consistently through a variety of media (verbal language, drawing, play-dough modelling). Investigations such as those undertaken in the current study suggest that imagery plays an important role in building concept-skill, particularly dynamic modes.

Second, there is also some evidence (hard won since it is difficult to capture under openended interview conditions) of switching between everyday and scientific language modes instantaneously. These instances suggest switching between alternative images such as in explaining sunset. That these are not 'slips-of-the-tongue' is borne out by supporting evidence from drawings and play-dough models - modes of representation that take time to recreate, suggesting that some reference image is being used as a model for the recreation at that particular time, but more dynamic and plastic than a mental model (see Bryce and Blown 2016). This was particularly evident in instances in our research where children would evidently change their minds and remodel their ongoing construction to correspond to what they had previously said or drawn, e.g. a 7-year-old child altering her ball-shaped Sun to add spikes to it then scrapping that to create a disc shape. She had at least three concepts in mind (approximately the scientific version, the storybook version and the everyday version) and settled on one.

It must be remembered that these two main findings pertain to young people's interview responses and, therefore, it is an extrapolation to claim that we should come to similar conclusions about pupils' reasoning during classroom exchanges. It would be safe to reckon that where teachers are engaged in careful one-to-one and small group discussions, especially when determined to spot difficulties and diagnose misunderstandings (or alternative frameworks to use Driver's 1981 term), what has been revealed in this research would certainly apply. Beyond that, in teaching more generally, we see no reason to believe that switching would not take place, simply that the frequency of it might be lower and instances of it less apparent. Our findings certainly corroborate the conclusions of those researchers concerned to scaffold children's learning with care, particularly those whom we cited earlier (e.g. see Niebert et al. 2012). In their work to help young people develop scientific language, teachers must work thoughtfully as they initially accept children's everyday language and then help them to appreciate and use more formalised, scientific expressions and ideas, encouraging cross-checks in multiple modalities wherever possible. Rather than aiming to replace everyday concepts with scientific ones, teachers and parents should recognise that both types of concepts coexist and afford the opportunity to scaffold from one to the other.

Third, the tendency to categorise children's everyday language as animistic is questionable and must be weighed against the counterargument that much common language is rich in figurative speech handed down through generations from parent to child. A quite specific observation about folklore concerning the Chinese subjects in the research reported above relates to the area where the research was conducted. The children in Changchun (Jilin Province) on the Northeast China Plain talk of the Sun going behind the mountains when there are no mountains visible at all. Interestingly, these children are the offspring of migrants from Hebei and Shandong, more mountainous regions to the south (see Gottschang and Lary 2000). On their move to Jilin, did the people take their folklore (including stories of the Sun and Moon going to rest behind mountains) with them? To investigate this question (within the broader context that folklore is a deeply embedded rich source of imagery), we conducted a 
follow-up study of parents of Shandong ancestry. We found that concepts of the Sun and Moon rising and setting behind mountains are indeed a common feature of local folklore and that these ideas have been passed on from generation to generation.

Fourth, the research which we have described indicates that children's grasp of scientific ideas in this field may ordinarily be under-estimated if one only goes by formal scientific expression and vocabulary. Again, generalising to the classroom, this has an awkward corollary in that recent educational movements are obliging young pupils to be familiar with scientific expressions at younger ages than in the past. In several countries, government pressures, stemming largely from international league table comparisons (like PISA), have resulted in curriculum change where there were more formalised treatments of science figure earlier in school. Handled clumsily, these can so easily run counter to sensible practice in teaching. Policies or practices which, intentionally or not, denigrate or prematurely discourage everyday modes of thinking are mistaken. As mentioned above, rather than attempting to replace everyday language with scientific language, as some researchers and educationalists have argued, we should recognise their coexistence (see Fleer and Ridgway 2007) and use the former as a basis to build (scaffold) the latter as originally advocated by Piaget and Vygotsky (see Vygotsky 2012), e.g. by analogy (see Niebert et al. 2012). The matter interestingly connects to research into the conditions under which learning is understood to transfer. According to Wagner, "Transfer is revealed not as rooted in the acquisition of increasingly abstract mental representations, but through the incremental refinement of knowledge resources that account for-rather than overlook — contextual variation” (Wagner 2010, p. 1).

Fifth, on encouraging the emergence of disembedded thought/language, teachers and parents could engage in unconventional teaching and learning experiences such as observing sunrise and sunset with their children and imagining the Earth moving (rotating) towards the Sun (sunrise) or away from the Sun (sunset). In other words, we have to give children "direct experience with phenomena" (Nussbaum and Novak 1976) to enable them to break away from traditional contexts. There is also a need to be more selective about the role of children's literature to ensure a balance between everyday and scientific perspectives or to use stories based on folklore to lead into alternative (scientific) explanation. Disembedding could also be enhanced by the use of media such as drawing and play-dough modelling to reinforce concepts being introduced by verbal language, so encouraging the growth of scientific reasoning.

Sixth, and again extrapolating beyond that which has been revealed from interview analyses, switching between everyday and scientific modes is not restricted to children or to modes. Adults commonly switch between modes of behaviour according to cultural tradition. For example, a teacher in New Zealand may switch from teaching science to preparing to celebrate Christmas with her family or a parent in China may switch from manufacturing computer components to preparing food to celebrate the Spring Festival. Similar examples pertain to other cultures. Thus, the idea of coexisting modes should not surprise but rather should be acknowledged as a natural feature of the evolution of human behaviour, language and thought.

\section{Further Research}

The study indicates that researchers still have much to focus upon regarding the speech repertoires of young people. Future research can usefully follow several different leads opened up by the work described in this paper. Two areas are considered here. 


\section{How Embedded Is Animism?}

Researchers typically view the children's use of figurative speech and animism as one and the same thing: animism is figurative and is firmly grounded in the culture which young people experience. From such a perspective, early language derives from the particular folklore which children are immersed in. Bedtime stories, parental explanations, preschool play, guidance from peers and so forth all provide a repertoire of language which shapes how children learn to talk. In this view, animism and figurative speech are totally embedded. An alternative might be to distinguish between animism and figurative speech (which Piaget himself did not do) and to consider figurative speech rather more generally as disembedded - albeit an early and imperfect form (scientifically speaking) — but one which leads to a better understanding of subsequent scientific language. This is to propose that language switching may be more sophisticated than is generally acknowledged. Writers like Solomon (1983c) have emphasised the distinction between the embedded and disembedded modes of thought/language (the terms in italics were introduced by Donaldson 1978); perhaps these modes are more intertwined. In a nutshell then, we may be underestimating children's ability by labelling all of their figurative speech as animism. Difficult though it will be to research it may be important to investigate whether animistic expressions were derived from two repertoires of speech, not one-colloquial (or vernacular) language - and to consider whether (or how and when) figurative speech is not only animism but a form of disembedded thought/language which itself facilitates a grasp of better scientific language.

And as aforementioned, our research indicates that folklore (including animism, anthropomorphism, figurative speech and personification) is a major source if not the primary source of everyday concepts of the Earth, Sun and Moon. Exploring further the 'migration of folklore' (like the sleeping of the Sun or Moon behind the mountains) would make an interesting ethnological study for future research.

\section{Mental Imagery}

A second area for research, one which will require innovative technology to fully pursue, concerns the imagery which subjects use when reasoning. In the literature review, we raised Pylyshyn's (2003) question about whether images, such as those of the Earth, the Sun and the Moon (ESM), are spatially displayed pictures or some other forms of analogous representation. The research conducted here raises the question of whether new insights could be gained by asking children to describe in greater detail how they visualise the shape of ESM (static imagery) and the motion of ESM (dynamic imagery) and repeating the same questions some weeks or months later to see if the same descriptions are repeated. Disentangling individual's capabilities of developing dynamic imagery from static imagery as a result of key life experiences (including the interviewing itself) will be difficult. In the future, when brain scanning technologies become more sophisticated, it may of course prove possible to scan brain activity areas for both their location and the nature of the images (static versus active) sensed by a person in response to questions posed.

\section{Finally}

Attention should be paid by researchers and teachers to the awkward uses of 'rotation' and 'revolution' in common speech. Children's spinning tops rotate and, for comparison purposes, 
do simulate the way in which the Earth moves to yield day and night; playground roundabouts go 'round and round', and again for comparison purposes, a teacher might say that a person on the outside is revolving around the centre, just like the Earth goes round the Sun. 'Spinning' and 'going round and round' are everyday/spontaneous concepts based on embedded cultural contexts which need to be distinguished to become the scientific concepts of rotation and revolution, respectively. However, some large department stores have doors which spin, but adults generally say that these are revolving doors - adding to puzzlement when the teachers' scientific language describes the Earth's movement around the Sun as a revolution. And this mix-up is compounded where inaccurate children's literature attributes daytime and night-time to the revolution of the Earth around the Sun rather than the rotation of the Earth on its axis and, in a small minority of cases, where uses of the terms rotation and revolution treat them as if they were synonyms. Piaget said that adult language is unhelpfully childish at times; he could well have added that adult language is often downright confusing.

Open Access This article is distributed under the terms of the Creative Commons Attribution 4.0 International License (http:/creativecommons.org/licenses/by/4.0/), which permits unrestricted use, distribution, and reproduction in any medium, provided you give appropriate credit to the original author(s) and the source, provide a link to the Creative Commons license, and indicate if changes were made.

\section{References}

Aikenhead, G. (2011). Towards a cultural view on quality science teaching. In D. Corrigan, J. Dillon, \& R. Gunstone (Eds.), The professional knowledge base of science teaching (pp. 107-127). New York: Springer.

Ash, D. (2004). Reflective scientific sense-making dialogue in two languages: the science in the dialogue and the dialogue in the science. Science Education, 88(6), 855-884.

Bailey, J.M., Coble, K., Cochran, G., Larrieu, D., Sanchez, R., \& Cominsky, L.R. (2012). A multi-institutional investigation of students' preinstructional ideas about cosmology. Astronomy Education Review. AER, 11, 010302-1,10.3847/AER2012029.

Bar, V., Zinn, B., \& Rubin, E. (1997). Children's ideas about action at a distance. International Journal of Science, 19(10), 1137-1157.

Barsalou, L. W. (2003). Situated simulation in the human conceptual system. Language and Cognitive Processes, 18(5/6), 513-562.

Blown, E. J., \& Bryce, T. G. K. (2006). Knowledge restructuring in the development of children's cosmologies. International Journal of Science Education, 28(12), 1411-1462.

Blown, E. J., \& Bryce, T. G. K. (2010). Conceptual coherence revealed in multi-modal representations of astronomy knowledge. International Journal of Science Education, 32(1), 31-67.

Blown, E. J., \& Bryce, T. G. K. (2012). Thought-experiments about gravity in the history of science and in research into children's thinking. Science and Education, 22(3), 419-483.

Bowie, B. (Producer) \& Finnegan, S. (Director). (2013). Hawking [Film and TV Documentary]. England: Channel 4.

Brown, B. A., \& Ryoo, K. (2008). Teaching science as a language: a "content-first" approach to science teaching. Journal of Research in Science Teaching, 45(5), 529-553.

Brown, B. A., \& Spang, E. (2008). Double talk: synthesizing everyday and science language in the classroom. Science Education, 92(4), 708-732.

Brown, B. A., Ryoo, K., \& Rodriguez, J. (2010). Pathway towards fluency: using "disaggregate instruction" to promote science literacy. International Journal of Science Education, 32(11), 1465-1493.

Bruner, J. S. (1966). Towards a theory of instruction. Cambridge: Harvard University Press.

Bruner, J. (1986). Actual minds, possible worlds. Cambridge: Harvard University Press.

Bryce, T. G. K., \& Blown, E. J. (2006). Cultural mediation of children's cosmologies: A longitudinal study of the astronomy concepts of Chinese and New Zealand children. International Journal of Science Education, 28(10), 1113-1160.

Bryce, T. G. K., \& Blown, E. J. (2007). Gender effects in children's development and education. International Journal of Science Education, 29(13), 1655-1678. 
Bryce, T. G. K., \& Blown, E. J. (2012). The novice-expert continuum in astronomy knowledge. International Journal of Science Education, 34(4), 545-587.

Bryce, T. G. K., \& Blown, E. J. (2013). Children's concepts of the shape and size of the Earth, Sun and Moon. International Journal of Science Education, 35(3), 388-446.

Bryce, T. G. K., \& Blown, E. J. (2016). Manipulating models and grasping the ideas they represent. Science and Education, 25(1), 47-93.

Donaldson, M. (1978). Children's minds. Glasgow: William Collins and Sons.

Driver, R. H. (1981). Pupils' alternative frameworks in science. European Journal of Science Education, 3(1), 93-101.

Driver, R., Newton, P., \& Osborne, J. (2000). Establishing the norms of scientific argumentation in classrooms. Science Education, 84, 287-312.

Edelman, G. M. (2005). Wider than the sky: a revolutionary view of consciousness. London: Penguin.

Fleer, M. (2009). Understanding the dialectical relations between everyday concepts and scientific concepts within play-based programs. Research in Science Education, 39(2), 281-306.

Fleer, M., \& Ridgway, A. (2007). Mapping the relations between everyday concepts and scientific concepts within playful learning environments. Research Online. http://ro.uow.edu.au/llrg/vol1/iss 1/2

Foley, J. (1994). Scaffolding. ELT Journal, 48(1), 101-102.

Frick, A., Duan, M. M., Wilson, M., \& Wilkening, F. (2009). Effects of action on children's and adult's mental imagery. Journal of Experimental Child Psychology, 104, 34-51.

Funk, M., Brugger, P., \& Wilkening, F. (2005). Motor processes in children's imagery: the case of mental rotation of hands. Developmental Science, 8, 402-408.

Gottschang, T. R., \& Lary, D. (2000). Swallows and settlers - the great migration from North China to Manchuria. Michigan Monographs in Chinese Studies, Centre for Chinese Studies, University of Michigan, Ann Arbor.

Greeno, J. G. (2012). Concepts in activities and discourses. Mind, Culture, and Activity, 19(3), 310-313.

Gribben, J., \& Gribben, M. (1998). Almost everyone's guide to science. London: Weidenfeld \& Nicolson.

Hsu, P.-L., \& Roth, W.-M. (2014). From authoritative discourse to internally persuasive discourse: discursive evolution in teaching and learning the language of science. Cultural Studies of Science Education, 9(3), 729753. doi:10.107/s11422-012-9475-2.

Jane, B., \& Robbins, J. (2007). Intergenerational learning: grandparents teaching everyday concepts in science and technology. Asia-Pacific Forum on Science Learning and Teaching, 8(1), 1-18.

John-Steiner, V., Meehan, T. M., \& Mahn, H. (1998). A functional systems approach to concept development. Mind, Culture, and Activity, 5(2), 127-134.

Juvet, G. (1933). La structure des nouvelles théories physiques [The structure of the new physical theories]. Paris: Alcan.

Kallery, M., \& Psillos, D. (2004). Anthropomorphism and animism in early years science. Research in Science Teaching, 34, 291-311.

Kelemen, D., \& Rosset, E. (2009). The human function: teleological explanation in adults. Cognition, 111(1), $138-143$.

Kelemen, D., Rottman, J., \& Setton, R. (2012). Professional physical scientists display tenacious teleological tendencies: purpose-based reasoning as a cognitive default. Journal of Experimental Psychology: General. doi: $10.1037 / \mathrm{a} 0030399$.

Kozulin, A. (2012). Foreword to Thought and language by Lev Vygotsky. Revised and expanded edition. Cambridge, MA: MIT.

Lakoff, G., \& Johnson, M. (1980). The metaphorical structure of the human conceptual system. Cognitive Science, 4(2), 195-208.

Lemke, J. L. (1990). Talking science: language, learning and values. Norwood: Ablex.

Mercer, N., Dawes, L., Wegerif, R., \& Sams, C. (2004). Reasoning as a scientist: ways of helping children to use language to learn science. British Educational Research Journal, 30(3), 359-377.

Mooney, C. G. (2000). Theories of childhood: an introduction to Dewey, Montessori, Erickson, Piaget \& Vygotsky. St. Paul: Redleaf.

Newton, D. P. (2002). Talking sense in science: helping children understand through talk. London: RoutledgeFalmer.

Niebert, K., Marsch, S., \& Treagust, D. F. (2012). Understanding needs embodiment: a theory-guided reanalysis of the role of metaphors and analogies in understanding science. Science Education, 96(5), 849-877.

Nussbaum, J. (1979). Children's conceptions of the Earth as a cosmic body: a cross age study. Science Education, $63,83-93$.

Nussbaum, J., \& Novak, J. D. (1976). An assessment of children's concepts of the Earth utilizing structured interviews. Science Education, 60, 535-550. 
Petrie, H. G. (1979). Metaphor and learning. In A. Ortony (Ed.), Metaphor and thought (pp. 438-461). Cambridge: Cambridge University Press.

Piaget, J. (1959). The language and thought of the child (M. Gabain Trans.). London: Routledge \& Kegan Paul. (Original work published 1926).

Piaget, J. \& Inhelder, B. (1971). Mental imagery in the child: a study of the development of imaginal representation. (P. A. Chilton Trans.). London: Routledge \& Kegan Paul. (Original work published 1966).

Postman, N., \& Weingartner, C. (1971). Teaching as a subversive activity. London: Penguin/Pitman.

Pylyshyn, Z. W. (2003). Return of the mental image: are there really pictures in the brain? Trends in Cognitive Science, 7, 113-118.

Renshaw, P., \& Brown, R. A. J. (2007). Formats of classroom talk for integrating everyday and scientific discourse: replacement, interweaving, contextual privileging and pastiche. Language and Education, 21(6), $531-549$.

Solomon, J. (1983a). Learning about energy: how pupils think in two domains. European Journal of Science Education, 5(1), 49-59.

Solomon, J. (1983b). Messy, contradictory and obstinately persistent: a study of children's out-of-school ideas about energy. School Science Review, 225-229.

Solomon, J. (1983c). Thinking in two worlds of knowledge. In H. Helm \& J. D. Novak (Eds.), Proceedings of the international seminar on misconceptions in science and mathematics (pp. 146-151). Ithaca: Department of Education, Cornell University.

Taber, K. S. (2000). Multiple frameworks? Evidence of manifold conceptions in individual cognitive structure. International Journal of Science Education, 22(4), 399-417.

Tenenbaum, H. R., \& Callanan, M. A. (2008). Parents' science talk to their children in Mexican-descent families residing in the USA. International Journal of Behavioral Development, 32(1), 1-12.

van Oers, B. (1998). The fallacy of detextualization. Mind, Culture, and Activity, 5(2), 135-142.

Venville, G. J., Louisell, R. D., \& Wilhelm, J. A. (2012). Young children's knowledge about the Moon: a complex dynamic system. Research in Science Education, 42(4), 729-752.

Vosniadou, S. (1989). Analogical reasoning as a mechanism in knowledge acquisition: a developmental perspective. In S. Vosniadou \& A. Ortony (Eds.), Similarity and analogical reasoning (pp. 146-178). Cambridge: Cambridge University Press.

Vygotsky, L. (2012). Thought and language (A. Kozulin, Ed. \& Trans). Cambridge, MA: MIT. (Original work published 1934).

Wagner, J. F. (2010). Transfer in pieces. Cognition and Instruction, 24(1), 1-71.

Wellington, J., \& Osborne, J. (2001). Language and literacy in science education. Buckingham: Open University Press. 